\title{
Longitudinal Patterns of Ethical Organisational Culture as a Context for Leaders' Well-Being: Cumulative Effects Over 6 Years
}

\author{
Mari Huhtala $^{1}$ (1) $\cdot$ Muel Kaptein $^{2} \cdot$ Joona Muotka $^{1} \cdot$ Taru Feldt $^{1}$
}

Received: 3 March 2020 / Accepted: 13 January 2021 / Published online: 2 February 2021

(c) The Author(s) 2021

\begin{abstract}
The aim of this longitudinal study was to investigate the temporal dynamics of ethical organisational culture and how it associates with well-being at work when potential changes in ethical culture are measured over an extended period of 6 years. We used a person-centred study design, which allowed us to detect both typical and atypical patterns of ethical culture stability as well as change among a sample of leaders. Based on latent profile analysis and hierarchical linear modelling we found longitudinal, concurrent relations and cumulative gain and loss cycles between different ethical culture patterns and leaders' well-being. Leaders in the strongest ethical culture pattern experienced the highest level of work engagement and a decreasing level of ethical dilemmas and stress. Leaders who gave the lowest ratings on ethical culture which also decreased over time reported the highest level of ethical dilemmas, stress, and burnout. They also showed a continuous increase in these negative outcomes over time. Thus, ethical culture has significant cumulative effects on well-being, and these longitudinal effects can be both negative and positive, depending on the experienced strength of the culture's ethicality.
\end{abstract}

Keywords Ethical culture $\cdot$ Longitudinal patterns $\cdot$ Ethical strain $\cdot$ Burnout $\cdot$ Work engagement $\cdot$ Leaders

\section{Introduction}

Sustainable and responsible practices in organisations are becoming increasingly significant in today's working life. Of the different elements that can support ethical actions within organisations, ethical culture is seen as an important, if not the most important component (Kaptein 2011). It refers to the experiences, presumptions, and perceptions of how unethical behaviour is prevented and how ethical

Mari Huhtala

mari.huhtala@jyu.fi

Muel Kaptein

mkaptein@rsm.nl

Joona Muotka

joona.s.muotka@jyu.fi

Taru Feldt

taru.feldt@jyu.fi

1 Department of Psychology, University of Jyväskylä, PO Box 35, 40014 Jyväskylä, Finland

2 Department of Business-Society Management, Rotterdam School of Management, Erasmus University Rotterdam, Burgemeester Oudlaan 50, 3062 PA Rotterdam,

The Netherlands behaviour is promoted in one's organisation (Treviño and Weaver 2003). However, research on organisational ethics has been strongly dominated by cross-sectional studies, even up to $90 \%$ (see Huhtala et al. 2018; Mayer 2014; McLeod et al. 2016, for reviews). We therefore lack evidence of the long-term effects ethical culture might have on individuals. The goal of this study was to explore temporal patterns of ethical culture and whether these patterns of stability and/or change associate with leaders' long-term well-being. Thus, we contribute to understanding the potential health-promoting or -hampering effects of ethical culture in organisations and the strength and direction of these associations within and between individuals over multiple time points.

To date, only two studies have used longitudinal designs to investigate ethical culture. Huhtala et al. (2016) identified patterns of both ethical culture stability and change across two measurement points, and showed they were related to different well-being effects. Kangas et al. (2018) showed that a low level of ethical culture predicted turnover over 2-year and 4-year periods. However, neither of these investigations identified temporal changes beyond two measurement points. In the current study we used a four-wave, 6-year follow-up data that enabled us to identify different profiles of ethical culture that might include 
not only stable patterns or patterns that show a continuous decrease or increase, but also more dynamic changes from strong, stable ethical culture to declined ratings or vice versa. Another important question that has not been addressed by previous research concerns the time lag that would be necessary for the proposed link between ethical culture strength and well-being to appear. We used multiple measurements of personal evaluations of both ethical culture and well-being, allowing us to investigate their temporal relationships for the first time. For example, if a person's experience of ethical culture changes over time (either because they moved into a new organization or because the practices had changed in their current company), does it co-occur with simultaneous changes in personal well-being?

When studying longitudinal effects, there are two fundamentally different approaches to conduct such analyses (see Spurk et al. 2020; Woo et al. 2018). First is the more traditional variable approach, which is well suited for studying the importance of different predictor variables in explaining variance in outcome variables (e.g., structural equation modelling, such as cross-lagged panel studies; Spurk et al. 2020). However, these designs can provide information only about the average estimates across the whole population, and they assume that the studied population is homogeneous regarding the predictor-outcome associations. Variable-centred analyses also do not enable detecting the aforementioned different patterns of change over time. The second approach focuses on the person instead of the variable. Whereas the variable approach overlooks the possibility that the relations between variables can differ both quantitatively and qualitatively among individuals, the person approach can detect atypical patterns and minority groups from the whole population. Put differently, the person approach enables to study individual differences in patterns over time and different longitudinal associations among them (Howard and Hoffman 2018). Despite the calls to utilise the person approach also in work and organisational research, it remains to be only marginally used compared to continuous latent variable models (see Spurk et al. 2020; Woo et al. 2018 for reviews).

The final contribution of this study comes from using the aforementioned person-oriented approach, more specifically, a latent profile analysis, (Spurk et al. 2020). We aimed to identify potential subgroups of leaders based on their evaluations of ethical culture over time. These subgroups were then compared in relation to the leaders' personal well-being over time. Our main argument is based on the conservation of resources theory (Hobfoll 1989): We suggest that working in an ethical culture can provide several organisational resources for employees that can form cumulative cycles of resource gain (or loss, if the ethical culture is experienced to weaken) over time. These cumulative cycles can have different long-term effects on leaders' well-being. Next, we will describe the central theoretical models of this study and set our study hypotheses based on these frameworks.

\section{Ethical Culture as a Part of the Organisational Context}

There are two main components that comprise the ethical context of organisations. First is formal, also referred to as the "hard controls", which includes the concrete and explicit plans, policies, and procedures within the organisation (see Kaptein 2011). Of these formal systems, ethics programs are most relevant as it comes to promoting ethical behaviours: they include a code of ethics and different practices such as ethics training sessions, monitoring systems, and whistle-blowing policies (Treviño and Weaver 2003). The second is informal, also known as the "soft controls". This component includes the implicit, intangible elements, such as the values, expectations, and assumptions that prevail in the organisation. Two most central concepts in business ethics that are used to capture this informal context are ethical climate and ethical culture (Kaptein 2011). The former includes perceptions among organisational members about what constitutes (un)ethical behaviour (Victor and Cullen 1987), whereas the latter refers to the perceptions of the conditions that are available for ethical behaviour. Thus, ethical climate represents the content-related, substantive part of the organisational context, and ethical culture represents the procedural elements.

From the contextual elements of organisational ethics, ethical culture is most likely to affect personal well-being at work because of its procedural nature. We used the Corporate Ethical Virtues model (CEV; Kaptein 2008, 2011) to conceptualize ethical culture, which focuses especially on organisations as moral entities and takes a normative stand towards ethical culture. According to Kaptein (2008), ethical culture is characterised by eight dimensions that "reflect the capacity of an organisation to stimulate ethical conduct of employees" (p. 924). The CEV model continues to represent one of the most elaborately developed ethical culture models for business, derived from an analysis of 150 practices of unethical behaviour (Kaptein 1998). In addition, this model offers an evidence-based instrument for measuring ethical culture, which has been broadly tested for its empirical validity (DeBode et al. 2013; Huhtala et al. 2018; Kangas et al. 2014; Kaptein 2008, 2011). Thus, it provides a reliable and valid way to operationalise ethical culture.

The CEV model was developed on the basis of existing theory and empirical research, and validated by four interlocking studies (Kaptein 2008). It includes eight dimensions, which are clarity, congruency of supervisors, congruency of senior management, feasibility, supportability, transparency, discussability, and sanctionability. 
Clarity represents norms for ethical behaviour, the ethical standards within the organisation that should be concrete, comprehensive, and understandable. Congruency of supervisors and congruency of senior management reflect managerial behaviours that should be ethical. If leaders behave unethically, they are going against the existing ethical standards and represent poor ethical role models to employees, signalling that unethical actions can be overlooked or even positively allowed. Feasibility refers to concrete possibilities and resources that enable ethical actions: Organisational members need sufficient time, financial resources, equipment, and information, as well as the personal authority to act according to norms and values without feeling pressured to violate ethical standards. Supportability represents motivation for ethical behaviour. It means the fair treatment of employees and an atmosphere of trust within the organisation, which creates a shared commitment to ethical behaviours. Transparency increases employees' awareness of the consequences of their actions and acts as a deterrent to unethical behaviour, because it means that behaviours and their consequences are perceptible to organisational members. Discussability refers to the opportunity to raise and discuss ethical issues at work, which can increase the sharing of knowledge and provide support in the face of ethical problems. Finally, sanctionability represents enforcement of ethical behaviour. It means that in an ethical organisation its members are rewarded for ethical behaviour and punished for behaving unethically. A more detailed specification and discussion of the theoretical viewpoints on these virtues as sub-dimensions of an ethical organizational culture can be found in Kaptein $(2008,2011,2017)$.

In the current study we focus on the overall quality of ethical culture as an individual experience, using a composite measure from all the aforementioned eight dimensions. Although they represent different conditions for ethical behaviour, together they comprise the whole ethical culture. For example, an organisation that has clear norms and expectations for ethical behaviour (high clarity), but leaders who undermine the common rules (low congruency) or insufficient resources for ethical actions (low feasibility) cannot truly be described to have an ethical culture. In addition, based on previous empirical studies the eight dimensions have high intercorrelations, and factor analyses have shown that they originate from an encompassing construct of the ethical organisational culture (DeBode et al. 2013; Huhtala et al. 2018; Kangas et al. 2014; Kaptein 2008). In more practical terms, the different dimensions are highly dependent with each other while capturing somewhat different sides of the whole. These justifications, both theoretical and methodological, lead us to use a composite score of ethical culture instead of focusing on each dimension separately.

\section{Outcomes of Ethical Culture}

We used four indicators that represented different longitudinal outcomes of ethical culture in the current study. First of all, we examined individual experiences of ethical dilemmas, that is, situations that require consideration of what is right or wrong (Treviño 1986). They can be situations of uncertainty, where it is not clear which of the potential alternatives is the right option. Another type of dilemma are situations where one knows what is right, but it is impossible to apply one's values in practice (Nash 1993). In these cases, the employee recognises the appropriate action that a situation requires but cannot carry out that action because of institutional obstacles (e.g., lack of time or lack of supervisory support). We propose that the more ethical the organisational culture is experienced to be, the less ethical dilemmas the individuals report. This is because the ethical culture can provide organisational resources that help individuals to solve ethical dilemmas (Kaptein 2008). For example, discussability facilitates talking about ethical issues at work. This can promote shared learning, feedback, and social support, all of which help employees to solve the dilemmas they face. Strongly embedded ethical culture also make it less probable that an employee will be unable to follow their personal values because of organisational obstacles. Rather, strong feasibility, for example, makes it possible to carry out ethical decisions.

Our second outcome is the individual experience of ethical stress caused by facing ethical dilemmas (DeTienne et al. 2012; Huhtala et al. 2011). Whereas the frequency of dilemmas can be more directly related to, or even partially overlapping with the quality of the ethical culture (e.g., clarity means that the organisation provides clear norms and ethical guidelines, which can directly relate to a decreased frequency of dilemmas), stress caused by the dilemmas is more dependent on how a person experiences and interprets the dilemmas. Investigating stress explicitly stemming from ethical issues has its roots in the field of nursing science (Jameton 1984; Wilkinson 1987), but it has been acknowledged and studied also in the field of management (Waters and Bird 1987). Most of the conceptualisations agree that ethical stress emerges when personal values or responsibilities are in conflict with external constraints (see DeTienne et al. 2012, for a review). We propose that a strong ethical culture can lead to lower levels of ethical stress. For example, even if the job includes solving difficult ethical dilemmas, being a part of a work community that is characterised by mutual trust and respect (i.e., high supportability, Kaptein 2008) might help to deal with these situations and therefore lower the employee's ethical stress levels.

The last two outcomes of the current study concerned two more traditional concepts that are often used 
to represent employee well-being: burnout and work engagement (see Bakker et al. 2014, for a review). Burnout is created by a slow process of progressive loss of energy and enthusiasm at work, which is characterised by feelings of emotional exhaustion, a cynical and distant attitude towards one's work, and a decline in one's feelings of competence and achievement at work (Bakker et al. 2014). Work engagement is a positive state of wellbeing, as engaged employees have a sense of effectiveness, energy, and strong identification with their work. Job-related resources have been shown to have a positive effect on work engagement, and a consistent, although less strong, negative relationship with burnout (Bakker et al. 2014). These outcomes were chosen because they are typical long-term reactions to the ways work conditions are experienced, and are thus in line with our 6-year followup design. This way our study responds to the need to conduct more multi-wave studies over longer time periods that focus on both positive and negative experiences of well-being (Mäkikangas et al. 2016).

\section{Ethical Culture and Well-Being: Conservation of Resources Theory}

In order to understand how ethical culture of organisations can act as a relevant factor for the aforementioned well-being outcomes, both environmental and internal processes need to be taken into account. Stevan Hobfoll's influential conservation of resources (COR) theory (1989) offers an integrative framework that considers both the objective circumstances (which can expose the individual to stress) and the individual's reactions when he/she is confronted with these environmental circumstances. Applied to our study context, we were interested in how individuals experience the quality of their organisation's ethical culture, and whether these experiences lead to different well-being reactions among them.

The COR theory starts from the basic premise that individuals strive to obtain, retain, foster, and protect those things they centrally value-that is, their resources (Hobfoll 2001). Resources are defined as objects or conditions that are valued in their own right, or that are valued because they enable the achievement or protection of other valued resources (Hobfoll 2001). By definition, a strong ethical culture will provide several important resources for employees and leaders, such as clear expectations, support for ethical decisions, and practical conditions (such as time and personal authority) that support carrying out ethical behaviour (Kaptein 2008). Previous (cross-sectional) studies have provided empirical support to the different positive effects that can result from working in an ethical organisational environment. Such examples include higher job satisfaction and commitment (Schwepker 2001), reduced stress and perceptions that the job is meaningful (Jaramillo et al. 2013), mitigated negative influences of external locus of control (Mulki and Lassk 2019), and increased perceptions of procedural and distributive justice, further leading to affective commitment and less turnover (Baker et al. 2006).

However, a culture that is experienced as less ethical can represent a stressful work environment to the employees. Organisations that lack a strong ethical culture can be characterised by vagueness and ambiguity of ethical expectations, unethical leadership, and unfair treatment (Kaptein 2017). In such an environment, employees' are likely to experience resource loss: they may be unable to carry out their responsibilities in an ethical manner because of limited resources, they lack ethical role models from their supervisors and managers, there is no room to discuss ethical problems, and the employees do not share a common motivation towards ethical behaviour (Kaptein 2017). When there is a threat that these organisational resources for ethical behaviour will be lost, when they actually are lost, or when they are insufficiently regained after a significant investment of resources, stress will occur. Resource loss is also experienced as disproportionally more salient than resource gain, leading to greater effects that take place rapidly and at increasing speed over time. Taken these theoretical premises together, we pose the following hypotheses for our study:

H1 Patterns with high or increasing levels of ethical culture are associated with beneficial outcomes (i.e., low number of ethical dilemmas, low levels of ethical stress, low levels of burnout, and high levels of work engagement).

H2 Patterns with low or decreasing ethical culture are associated with detrimental outcomes (high number of ethical dilemmas, high levels of ethical stress, high levels of burnout, and low levels of work engagement).

\section{Longitudinal Effects: Spirals of Resource Loss and Gain}

What makes the COR theory especially useful for understanding the long-term effects that ethical culture of organisations can have on well-being is that the theory takes into consideration the fact that stressful conditions are seldom specific events. Rather, they are sequences that occur over time, and these iterations of different events create spirals of both resource loss and gain (Hobfoll et al. 2018). Negative spirals take place when stress occurs after a loss of resources. Because resource loss is more powerful than resource gain, each new situation is approached with ever fewer resources, thus creating an escalating spiral, where losses gain more impact and momentum. For example, when an employee repeatedly faces ethical dilemmas with insufficient resources or support from the organisation to deal 
with them, it is likely to increase stress reactions, frustration, and cynicism in future dilemma situations. In contrast, because gaining resources is slower and of less magnitude than resource loss, positive resource gain spirals tend to be weaker and take more time to develop than loss cycles. In the long run, a significant resource depletion is likely to lead to defensive, even counterproductive reactions which can act as a strategy aimed at conserving resources for later action (Hobfoll 2001).

When investigating these kinds of loss and gain processes and stress reactions, using study designs with different time frames can provide different findings. Short-term effects can change when they are followed through over a longer period of time. For example, a stressor-strain association might diminish or even disappear over time as individuals get used to the long-term stressors and learn to adapt to them, perhaps through their improved use of resources (see Hobfoll et al. 2018). Relatedly, our 6-year longitudinal study enabled us to examine whether the associations between different patterns of ethical culture and well-being would produce similar or deviant results that the 2-year study by Huhtala et al. (2016).

Even though the COR theory has been used to test the interplay over time between work place conditions and well-being (see Halbesleben et al. 2014; Hobfoll et al. 2018; Shipp and Cole 2015, for reviews), research on ethical culture as an organisational resource has been dominated by cross-sectional studies. Only one previous study has investigated the longitudinal effects of organisational ethical culture on personal well-being: Huhtala et al. (2016) found that when ethical culture was perceived to be deeply and stably embedded in the organisation during a 2-year follow-up, this associated with enduringly high levels of well-being. They also found that when individuals reported an increase in their organisation's ethical culture during the 2 years, they did not experience a similar decline in their well-being to that suffered by those who had initially perceived their organisation to have either a low or a decreasing level of ethical culture. This led Huhtala et al. (2016) to conclude that a stable, high level of ethical culture is related to most favourable psychological outcomes, and ethical culture that become stronger over time can act as protective factor that helps to maintain well-being. This interpretation is in line with the COR theory, which states that gain spirals are slow and difficult to create (Hobfoll 2001). Thus, although an experienced increase in the level of organisational ethical culture can buffer against more negative outcomes, it does not necessarily or immediately lead to improved well-being. On the negative side, reactions related to a declining ethical culture were found to be more detrimental to individual well-being than working in an organisation with a stably lower ethical culture: declining ethical culture was found to associate with increased cynicism and reduced work engagement (Huhtala et al. 2016).
We investigated the effects of a potentially accumulating resource loss (experiences of a low level of ethical culture), which is a prolonged stressor that exposes individuals to burnout. We also focused on positive resource accumulation (experienced strong ethical culture), which could lead to gain cycles and increased work engagement (see Schaufeli et al. 2009). Based on the spirals of resource loss and gain in the COR theory and on the previous findings on longitudinal effects of ethical culture, we pose the following hypotheses:

H3 Patterns that show positive stability over time, i.e., stable, strong evaluations of ethical culture, associate with the most beneficial outcomes (i.e., lowest number of ethical dilemmas, lowest levels of ethical stress, lowest levels of burnout, and highest levels of work engagement).

H4 Patterns that show negative stability over time, i.e., stable, low evaluations of ethical culture, lead to the most detrimental outcomes (i.e., highest number of ethical dilemmas, highest levels of ethical stress, highest levels of burnout, and lowest levels of work engagement).

\section{Context of the Study: Leaders' Perceptions of Ethical Culture}

Leaders were the focus of our study because of their unique status as decision-makers and role models within organisations. Leaders have been found to face complex and demanding situations at work, stemming from the uncertainty of trying to address multiple stakeholder claims (e.g., from subordinates, higher executives, and customers) (Bird and Waters 1987). They can experience a lack of clarity about specific appropriate behaviour while at the same time feel a general obligation to act in accordance with the ethical norms of the organisation (Waters and Bird 1987). This means they can feel uncertain about how to make morally appropriate decisions, and this can increase strain and thus present a risk to their well-being. We chose to focus on leaders who mostly represented the private sector $(80 \%$ of the study participants; others worked, for example, in the local government sector). As private organisations can be materialistic and mainly driven by profit (Van der Wal et al. 2008), it is of particular importance to study how leaders experience their ethical cultures within this work context, and how it can either support or threaten their well-being.

Because we were interested in the gain and loss spirals of ethical culture, we chose to study perceptions of individual leaders instead of organisational samples. This gave us access to a broader range of individual perceptions over time; following the members of only one organisation would have provided much more limited evidence of the potential gain and loss patterns and their impact on 
well-being. This is because members from the same organisation would be more likely to share their perceptions of how ethical culture changes across time (i.e., have similar experiences of their organisation's ethical culture). We also chose to use participants across multiple locations, because attrition is an inevitable consequence of longitudinal research (Shipp and Cole 2015), and using this kind of broad sampling reduced the risk that participant drop-out might lead to inadequate sample size and statistical power. By using a person-centred design (Spurk et al. 2020), we aimed to identify subgroups of leaders who had similar perceptions of ethical culture over time. Thus, our aim was to discover heterogeneity in the sample and identify more detailed gain and loss patterns than would have been possible by using a variable-centred approach. Finally, we focused on individual perceptions of ethical culture (instead of a more "objective" or shared measurements of ethical culture) because perceptions can have a stronger influence on personal well-being outcomes than the actual characteristics of the organization: there is vast research that shows the importance of differentiating stressors (conditions and events causing subsequent reactions), perceived stress (perception and appraisal of the stressors), and strains (individual outcomes) (see Bliese et al. 2017). We also have evidence of the degree to which ethical culture evaluations were shared among people working in the same unit, which accounted only for $12-27 \%$ of the total variation (Huhtala et al. 2014). This means that there can also be individual variation in the perceptions of ethical culture, making it relevant to focus on the personal level.

\section{Method}

\section{Participants}

The sample included 567 leaders working in technical and commercial fields. They were selected from a broader longitudinal data collection $(\mathrm{T} 1=2009, \mathrm{~T} 2=2011, \mathrm{~T} 3=2013$, $\mathrm{T} 4=2015$ ) if they had participated a minimum of two out of four data waves. The 2 year intervals were chosen in order to capture longitudinal dynamics in ethical culture. Of these leaders, 179 participated all four times (32\%), 183 three times (32\%), and 201 twice (36\%). The full flowchart of the data collection is presented in Fig. 1. Table 1 presents the respondents' demographic information and other characteristics. We measured demographic variables at T1 (2009) and all other variables at T1 (2009), T2 (2011), T3 (2013), and T4 (2015).

\section{Measures}

\section{Ethical Culture}

We measured ethical culture by using the shortened 32-item version of the Corporate Ethical Virtues (CEV-32) scale (Kaptein 2008; see DeBode et al. 2013). The original CEV

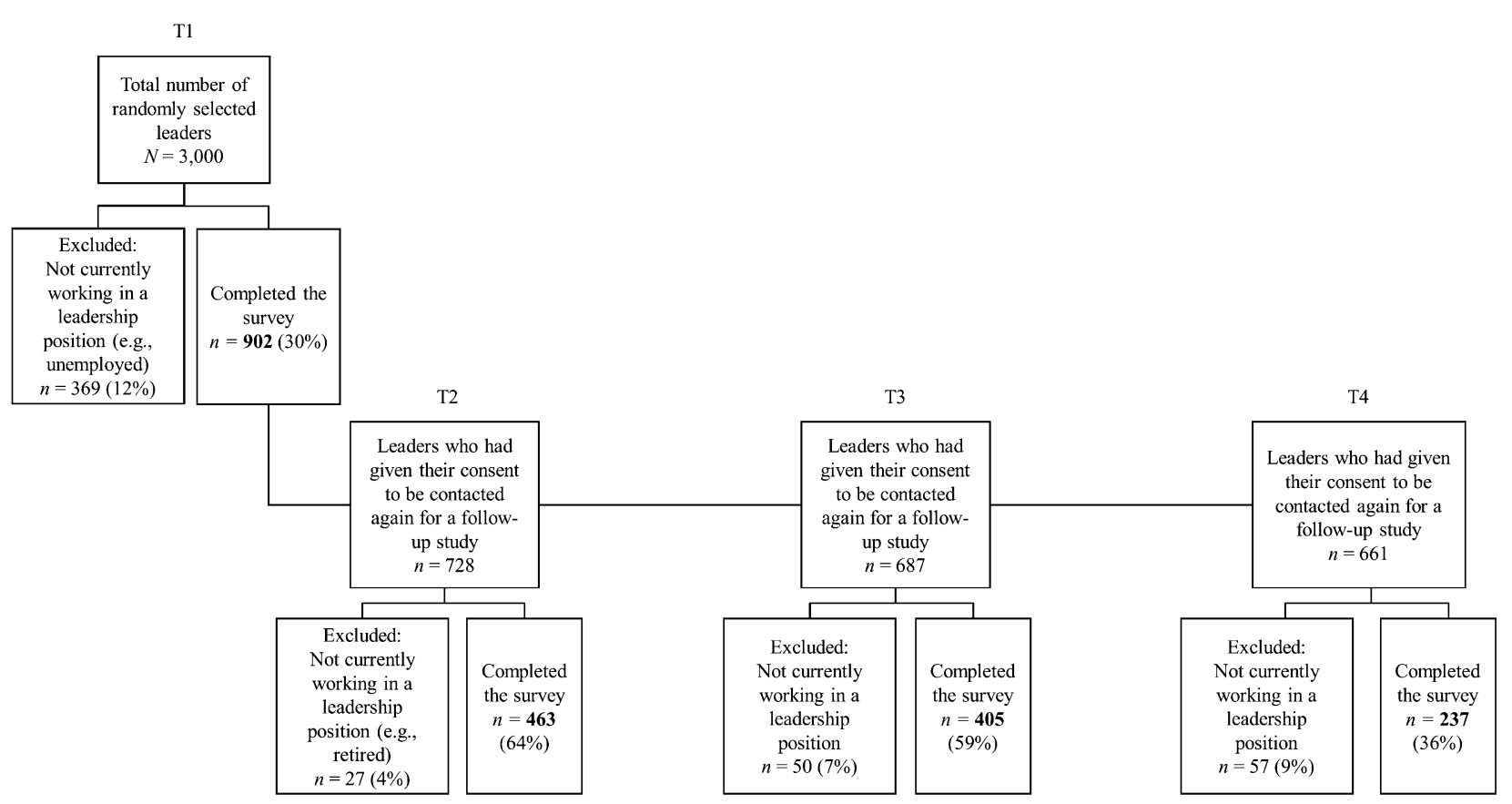

Fig. 1 Flowchart of the data collection 
Table 1 Sample characteristics

\begin{tabular}{|c|c|c|c|c|}
\hline & Time 1 & Time 2 & Time 3 & Time 4 \\
\hline Sample size $n$ & 567 & 463 & 403 & 237 \\
\hline \multicolumn{5}{|l|}{ Labour union $n(\%)$} \\
\hline Finnish business school graduates & $262(46.2)$ & & & \\
\hline Academic engineers and architects & $305(53.8)$ & & & \\
\hline \multicolumn{5}{|l|}{ Work contract $n(\%)$} \\
\hline Permanent & $557(98.2)$ & & & \\
\hline Temporary & $10(1.8)$ & & & \\
\hline \multicolumn{5}{|l|}{ Contract type $n(\%)$} \\
\hline Full time & $487(97.4)$ & & & \\
\hline Part time & $3(0.6)$ & & & \\
\hline Family leave & $7(1.4)$ & & & \\
\hline Temporary layoff & $3(0.6)$ & & & \\
\hline \multicolumn{5}{|l|}{ Employment sector $n(\%)$} \\
\hline Private & $451(79.8)$ & & & \\
\hline Municipality & $45(8.0)$ & & & \\
\hline Government & $40(7.1)$ & & & \\
\hline Own company & $18(3.2)$ & & & \\
\hline Association & $11(1.9)$ & & & \\
\hline \multicolumn{5}{|l|}{ Employment field $n(\%)$} \\
\hline Industry & $224(39.5)$ & & & \\
\hline Telecommunications/data processing & $81(14.3)$ & & & \\
\hline Business services/renting & $66(11.6)$ & & & \\
\hline Public administration & $50(8.8)$ & & & \\
\hline Finance and insurance & $44(7.8)$ & & & \\
\hline Commerce and trade & $39(6.9)$ & & & \\
\hline Education & $16(2.8)$ & & & \\
\hline Other (e.g., health care, traffic) & $47(8.3)$ & & & \\
\hline \multicolumn{5}{|l|}{ Leadership level $n(\%)$} \\
\hline Upper management & $72(12.7)$ & & & \\
\hline Management & $189(33.3)$ & & & \\
\hline Upper middle management & $210(37.0)$ & & & \\
\hline Lower middle management & $96(16.9)$ & & & \\
\hline \multicolumn{5}{|l|}{ Direct subordinates $n(\%)$} \\
\hline Yes & $455(80.4)$ & & & \\
\hline No & $111(19.6)$ & & & \\
\hline \multicolumn{5}{|l|}{ Gender $n(\%)$} \\
\hline Male & $386(68.1)$ & & & \\
\hline Female & $181(31.9)$ & & & \\
\hline \multicolumn{5}{|l|}{$M(\mathrm{SD})$} \\
\hline Age & $46(9.0)$ & & & \\
\hline Organisational tenure & $39(10.5)$ & & & \\
\hline Work experience in current task & $26(4.3)$ & & & \\
\hline Corporate ethical virtues & $4.33(0.75)$ & $4.43(0.73)$ & $4.45(0.76)$ & $4.65(0.77)$ \\
\hline Ethical dilemmas & $2.24(0.88)$ & $2.21(0.84)$ & $2.14(0.88)$ & $2.10(0.90)$ \\
\hline Ethical stress & $2.18(0.60)$ & $2.21(0.67)$ & $2.15(0.65)$ & $2.07(0.65)$ \\
\hline Burnout & $2.94(0.79)$ & $2.94(0.83)$ & $2.84(0.82)$ & $2.83(0.81)$ \\
\hline Work engagement & $5.83(0.98)$ & $5.81(1.00)$ & $5.80(0.97)$ & $5.79(1.03)$ \\
\hline
\end{tabular}


has altogether 58 items representing the eight dimensions, whereas the CEV-32 scale includes four items per each dimension (all 32 items can be found in Huhtala et al. 2018). Example items are "The organisation makes it sufficiently clear to me how I should deal with confidential information responsibly." (clarity); "My supervisor sets a good example in terms of ethical behaviour." (congruency of supervisors); "The conduct of the Board and (senior) management reflects a shared set of norms and values." (congruency of senior management); "I am not asked to do things that conflict with my conscience in my immediate working environment." (feasibility); "In my immediate working environment, everyone has the best interests of the organisation at heart." (supportability); "If a colleague does something which is not permitted, my manager will find out about it." (transparency), "In my immediate working environment, there is ample opportunity for discussing moral dilemmas." (discussability); and "In my immediate working environment, ethical conduct is rewarded." (sanctionability). Participants rated these items on a Likert scale from 1 (strongly disagree) to 6 (strongly agree). All the items from the feasibility dimension were originally negatively worded and scored in reverse (Kaptein 2008). In the shortened version the items were reworded to reflect a positive context (DeBode et al. 2013). Thus, a higher score (range 1-6) indicates a higher level of ethicality for each dimension. The eight-factor structure (including a second-order factor for total ethical culture) of the original CEV scale has received empirical support for its validity (Huhtala et al. 2011), group invariance (Huhtala et al. 2018; Kangas et al. 2014), and invariance over time (Huhtala et al. 2016). This means that the items and subdimensions represent the total ethical culture, and capture it in a reliable and valid way across different study populations and time points. The Cronbach's alphas for this scale were 0.96 (T1), 0.96 (T2), 0.96 (T3), and 0.97 (T4).

\section{Ethical Dilemmas and Stress}

The participants were given the following description of an ethical dilemma formulated on the basis of Nash's (1993) theory: "One can face situations at work, where there is a need to evaluate the rightness and goodness of one's actions, choices or decisions. These situations can be ethically challenging, because it is unclear, what would be the right thing to do. In addition, one may have to act against rules, norms or personal values for one reason or another." After this description, the prevalence of ethical dilemmas was measured using the following question (see Huhtala et al. 2011): "How often do you face ethically challenging situations in your work?" The item was scored on a 4-point frequencybased rating scale from 1 (never) to 4 (almost every day), higher ratings indicating a higher dilemma frequency.
The ethical stress caused by these dilemmas was assessed with another question (Huhtala et al. 2011): "Do you experience stress due to these situations (described in the previous item)? Stress refers to feelings of tension, restlessness, nervousness or anxiety, or troubles sleeping as things are on one's mind all the time". This item was scored on a 4-point frequency-based rating scale from 1 (not at all) to 4 (very much), higher ratings indicating a higher magnitude of stress. This kind of single-item measure of stress symptoms has been supported for its validity in a study by Elo et al. (2003). We used ethical dilemmas and stress as separate variables, because they can show both positive and negative correlations (low dilemma frequency with high magnitude of stress or vice versa) depending on individual differences in recognising, experiencing, and reacting to ethical dilemmas.

\section{Burnout}

Burnout was assessed with exhaustion and cynicism, which are generally seen as the core dimensions of burnout (Schaufeli and Bakker 2004). Both dimensions were measured using the 9-item Bergen Burnout Inventory (BBI-9; Näätänen et al. 2003; Salmela-Aro et al. 2004), including three items for each (for descriptions of all burnout items, see Salmela-Aro et al. 2011), e.g., "I am snowed under with work" (exhaustion) and "I feel dispirited at work and I think of leaving my job" (cynicism). The items were rated on a 6-point frequency-based scale ranging from 1 (completely disagree) to 6 (completely agree), higher mean scores indicating a higher level of burnout. The Cronbach's alphas for the total scale were 0.83 (T1), 0.84 (T2), 0.85 (T3), and 0.84 (T4).

\section{Work Engagement}

Work engagement was measured with the short version of the Utrecht Work Engagement Scale (UWES-9, Schaufeli et al. 2006). The short version has shown good internal consistency and test-retest reliability (Schaufeli et al. 2006; Seppälä et al. 2009), and better factorial validity than the longer version when studied with Finnish occupational groups (Seppälä et al. 2009). The UWES-9 includes three dimensions that reflect the underlying dimensions of engagement: vigour ( 3 items; e.g., "At my job, I feel bursting with energy."); dedication (3 items; e.g., "My job inspires me."); and absorption (3 items; e.g., "I am immersed in my work.") (for all item content, please see Seppälä et al. 2009). Responses were given on a 7-point frequency scale from 1 (never) to 7 (every day), higher mean scores indicating a higher level of work engagement. The Cronbach's alphas for the total scale were 0.93 (T1), 0.93 (T2), 0.93 (T3), and 0.94 (T4). 


\section{Analyses}

\section{Dropout}

We tested the representativeness of the samples by comparing the available demographic data of respondents and non-respondents. At T1, the attrition analysis between survey respondents and non-respondents showed that women were slightly overrepresented among the participants $\left[\chi^{2}(1)=6.23, p=0.013\right]$, and they were on average 1 year older than the non-respondents $[t(1751)=2.69, p=0.010]$. Next, we tested if the leaders who had participated at two or more time points (coded as 0) differed from those who had dropped out (coded as 1). These results are presented in Table 2. At T1, the study participants were on average younger than the study drop-outs (mean $=45.82 / 47.37$ years) and they had on average shorter organisational tenure (mean $=10.50 / 11.86$ years) and work experience in their current task (mean $=4.31 / 5.16$ years). There were no other significant differences in the demographic variables between the two groups. Of the study variables, the participants reported more ethical dilemmas than the drop-outs (a few times a month $21 \% / 14 \%$, almost every day $4 \% / 2 \%$ ) and more work engagement $($ mean $=5.83 / 5.65)$.

To summarise, there were only small differences in age and tenure, and even smaller differences only in two core study variables (ethical dilemmas and work engagement)

Table 2 Attrition analyses between study participants $(n=567)$ and non-participants (dropped out after time $1, n=335$ )

\begin{tabular}{llll}
\hline & Estimate & df & $p$ \\
\hline Demographic variables & $\chi^{2}$ & & \\
Labour union & 0.64 & 1 & 0.425 \\
Work contract & 2.82 & 2 & 0.244 \\
Employer sector & 4.38 & 4 & 0.357 \\
Employment field & 5.23 & 7 & 0.632 \\
Leadership level & 1.34 & 3 & 0.720 \\
Direct subordinates & 0.35 & 1 & 0.553 \\
Contract type & 6.12 & 3 & 0.106 \\
Gender & 1.98 & 1 & 0.159 \\
& $t$ & & \\
Age & -2.38 & 660 & 0.018 \\
Organisational tenure & -2.05 & 618 & 0.041 \\
Work experience in current task & -2.27 & 557 & 0.024 \\
Other study variables & $\chi^{2}$ & & \\
Ethical dilemmas & 12.52 & 4 & 0.014 \\
Ethical stress & 2.11 & 3 & 0.551 \\
& $t$ & & \\
Corporate ethical virtues & 0.40 & 895 & 0.686 \\
Burnout & -1.38 & 896 & 0.167 \\
Work engagement & 2.44 & 626 & 0.015 \\
\hline
\end{tabular}

between those who dropped out of the study after T1 and those who participated two or more times. These differences may be partly caused by drop-out through retirement: 15 participants reported that they had retired after the first data collection, thus lowering the age and tenure distribution among the remaining sample.

\section{Measurement Invariance of the Ethical Culture Scale}

All the following analyses were performed using the Mplus program (version 8.0; Muthén and Muthén 1998-2017). We tested the longitudinal measurement equivalence of the CEV-32 scale by estimating a configural invariance model, which tests whether the same general factor structure holds for both time points without any equality constraints (for the full procedure see, e.g., Vandenberg and Lance 2000). This is the baseline model for subsequent restricted model comparisons. Next, we tested a metric invariance model, where the factor loadings were constrained to be equal across time. When comparing the more restricted model with the previous, less restricted model, we used the SatorraBentler scaled difference chi-square test (Satorra and Bentler 1999), which produces a non-significant loss of fit between the models if the equality assumption is supported. Because of the large number of parameters in the CEV model (32 variables, 8 factors, and one second-order factor) in relation to our sample size (there should be a 5:1 ratio of sample size to number of free parameters; Marsh et al. 1998) we tested the time invariance separately for each of the ethical culture dimensions.

As Table 3 shows, all the ethical culture dimensions provided good fit to the data: CFI and TLI values were above 0.90 and RMSEA values were less than 0.06 . The invariance of the factor loadings for each eight dimensions showed that all factors except supportability showed longitudinal invariance: the chi-square difference tests between the unrestricted model (configural) and the restricted model (metric, factor loadings set equal over time) were statistically insignificant.

\section{Latent Profile Analysis of Ethical Culture Patterns Over Time}

After establishing the invariance of the CEV-32 scale, we conducted latent profile analysis (LPA; Spurk et al. 2020) in order to identify longitudinal patterns of ethical culture. Because the number and characteristics of potential patterns are not predetermined, the LPA enables identifying the best fitting model that is based on how the variables of interest appear in the data. Compared with traditional, more commonly used cluster analysis, LPA has several advantages. LPA is a model-based approach, which generates estimates for each individual's group membership probability. It also allows for statistical testing of these models and analyses of their goodness of fit. Thus, LPA can be used to identify the 
Table 3 Measurement invariance of the corporate ethical virtues scale over time (across time 1 to time 4 )

\begin{tabular}{|c|c|c|c|c|c|c|c|}
\hline & df & $\chi^{2}$ & CFI & TLI & RMSEA & $\Delta \mathrm{df}^{1}$ & $\Delta \chi^{2}$ \\
\hline \multicolumn{8}{|l|}{ Clarity } \\
\hline Configural invariance & 98 & 321.96 & 0.92 & 0.91 & 0.051 & - & - \\
\hline Metric invariance & 107 & 332.52 & 0.92 & 0.91 & 0.049 & 9 & $8.93 \mathrm{~ns}$ \\
\hline \multicolumn{8}{|c|}{ Congruency of supervisors } \\
\hline Configural invariance & 98 & 393.36 & 0.95 & 0.94 & 0.058 & & \\
\hline Metric invariance & 107 & 403.97 & 0.95 & 0.94 & 0.056 & 9 & $9.11 \mathrm{~ns}$ \\
\hline \multicolumn{8}{|c|}{ Congruency of senior management } \\
\hline Configural invariance & 98 & 327.01 & 0.95 & 0.93 & 0.051 & & \\
\hline Metric invariance & 107 & 342.34 & 0.94 & 0.94 & 0.050 & 9 & $17.24 \mathrm{~ns}$ \\
\hline \multicolumn{8}{|l|}{ Feasibility $^{\mathrm{a}}$} \\
\hline Configural invariance & 93 & 277.68 & 0.92 & 0.90 & 0.047 & & \\
\hline Metric invariance & 102 & 291.35 & 0.92 & 0.91 & 0.046 & 9 & $14.23 \mathrm{~ns}$ \\
\hline \multicolumn{8}{|l|}{ Supportability } \\
\hline Configural invariance & 98 & 272.25 & 0.95 & 0.94 & 0.045 & & \\
\hline Metric invariance & 107 & 295.07 & 0.95 & 0.94 & 0.044 & 9 & $22.71 * *$ \\
\hline \multicolumn{8}{|l|}{ Transparency ${ }^{\mathrm{a}, \mathrm{b}}$} \\
\hline Configural invariance & 92 & 264.53 & 0.93 & 0.90 & 0.046 & & \\
\hline Metric invariance & 101 & 272.36 & 0.93 & 0.91 & 0.044 & 9 & $7.24 \mathrm{~ns}$ \\
\hline \multicolumn{8}{|l|}{ Discussability } \\
\hline Configural invariance & 98 & 207.77 & 0.97 & 0.97 & 0.035 & & \\
\hline Metric invariance & 107 & 224.00 & 0.97 & 0.97 & 0.035 & 9 & $16.35 \mathrm{~ns}$ \\
\hline \multicolumn{8}{|l|}{ Sanctionability ${ }^{\mathrm{a}}$} \\
\hline Configural invariance & 95 & 294.17 & 0.93 & 0.91 & 0.048 & & \\
\hline Metric invariance & 104 & 302.91 & 0.93 & 0.92 & 0.046 & 9 & $6.26 \mathrm{~ns}$ \\
\hline
\end{tabular}

${ }^{a}$ Error covariances have been freed between same items over time (CEV15; CEV16; CEV30)

${ }^{\mathrm{b}}$ Error covariances between similarly worded items (CEV21 and CEV22) have been freed at each time point

$* * p<0.01$

smallest number of distinct groups of similar individuals that best represent the patterns in the data. These groups are represented by a categorical latent variable. LPA does not require similar assumptions (such as normal distribution of the data) as many other forms of analysis. It is therefore less prone to statistical biases.

Based on the justifications presented in the theory section, LPA was based on longitudinal changes in the composite scores of ethical culture instead of the eight different dimensions. Thus, these reasons were both theoretical (the dimensions make up the ethical culture together as a whole) and methodological (the dimensions have shown high intercorrelations and high factor loadings to the second order factor of ethical culture). In addition, using all eight dimensions would have produced a highly complex combination of differing patterns. These patterns would have been difficult to investigate and interpret (both statistically and related to their content) in relation to leaders' well-being. Mean sum scores were used for the total ethical culture (instead of saved factor scores) because of the very high reliabilities of the CEV-32 scale (see the measures section).
We determined the appropriate number of latent groups on the basis of several statistical criteria (see Nylund et al. 2007; Spurk et al. 2020): log likelihood, the Adjusted Bayesian Information Criterion (aBIC), the Lo-Mendell-Rubin adjusted likelihood ratio test (LMR), the Vuong-Lo-Mendell-Rubin Likelihood Ratio Test (VLMR), and the Bootstrap Likelihood Ratio Test (BLRT). The smallest log likelihood and aBIC values indicate the best fitting model, whereas the LMR, VLMR and BLRT compare solutions with different numbers of latent groups. They provide a p-value that is used to determine if there is a statistically significant improvement in fit after adding one more class. The quality of the classification was evaluated with the entropy for the most likely latent group membership. Entropy values range from 0 to 1 , where high values indicate that the latent groups are highly discriminative and a value between 0.70 and 0.80 is considered to indicate a reliable solution (Celeux and Soromenho 1996).

We ran the LPAs in two samples. First, we included only those leaders who had remained in the same organisation during their study participation $(n=398)$. This 
was done to investigate the latent profiles that would represent ethical culture evaluations that pertain to the same context-that is, the potential changes in ethical culture scores were not due to the leaders rating a different organisation at different time points. Second, we included all leaders who had provided data from at least two time points between $\mathrm{T} 1$ and $\mathrm{T} 4(n=567)$ regardless of their organisational change. This analysis was done to compare the LPA results of this larger sample with the previous, smaller sample. If a similar solution would be obtained, our aim was to include the larger sample in the further well-being analyses that compares the ethical culture profiles between each other.

A larger sample size was needed because we faced the risk of not detecting true effects because of low statistical power. This risk emerged from adding the sub-group level to our analysis, where we studied whether the subgroups showed significant time, group, or time $\times$ group effects compared to each other (see, e.g., Maas and Snijders 2003; Snijders and Bosker 1993). Adding the subgroup level to the analysis meant that a larger sample size is needed in order to reach adequate statistical power to explain variation both within and across groups (see, e.g., Crilly 2013, p. 186). Therefore, we chose to keep the larger sample in our HLM analyses, after reporting that the CEV profiles were similar between the two tested samples, because it enabled us to keep the larger sample size and remain more statistical power in the group comparisons (see Spurk et al. 2020).

\section{Well-Being in Different Ethical Culture Patterns}

We used hierarchical linear modelling (HLM) to investigate changes in well-being over time between the ethical culture patterns. As the number of all participants fell from 567 (T1) to 237 (T4), in these circumstances using listwise deletion (including only those participants who had data for all the study variables from each measurement point) would have significantly reduced our sample size and statistical power. Therefore, we used MLR as the method of estimation, which is an Mplus option for full-information maximum likelihood. This enabled us to make use of all the available data, which is an important feature that reduces attrition in a longitudinal study. We used a group $\times$ time analysis, where the identified ethical culture patterns represented the grouping variable and the repeated measurements were used as time variable. Thus, we investigated (a) the mean level changes of wellbeing from T1-T2-T3-T4 (time effect), (b) the differences in the mean levels of well-being between ethical culture patterns at each time point (group effect), and (c) the interaction of these effects (i.e., the moderating effects of belonging to a certain ethical culture pattern on the changes in well-being over time).

\section{Results}

\section{Ethical Culture Patterns}

All alternative group solutions for both samples are presented in Table 4 . The estimation process was terminated
Table 4 Fit indices for the latent profile analysis of ethical virtues

\begin{tabular}{llllllll}
\hline $\begin{array}{l}\text { No. of } \\
\text { groups }\end{array}$ & Log likelihood & Entropy & aBIC & VLMR & LMR & BLRT & Group proportions $(n)$ \\
\hline 1 & -1886.349 & - & 3788.699 & - & - & - & 567 \\
& $(-1222.445)$ & & $(2467.397)$ & & & & $(398)$ \\
2 & -1633.675 & 0.72 & 3321.168 & 0.000 & 0.000 & 0.000 & 285,282 \\
& $(-1030.826)$ & $(0.74)$ & $(2109.480)$ & $(0.006)$ & $(0.007)$ & $(0.000)$ & $(253,145)$ \\
3 & -1535.069 & 0.70 & 3152.450 & 0.062 & 0.064 & 0.000 & $234,170,163$ \\
& $(-926.594)$ & $(0.78)$ & $(1923.335)$ & $(0.013)$ & $(0.013)$ & $(0.000)$ & $(207,110,81)$ \\
4 & -1494.563 & 0.69 & 3099.929 & 0.484 & 0.488 & 0.000 & $228,163,102,74$ \\
& $(-884.763)$ & $(0.76)$ & $(1867.994)$ & $(0.123)$ & $(0.127)$ & $(0.000)$ & $(149,109,75,65)$ \\
5 & -1468.199 & 0.75 & 3075.694 & 0.004 & 0.004 & 0.000 & $223,152,105,68,19$ \\
& $(-858.031)$ & $(0.76)$ & $(1839.852)$ & $(0.547)$ & $(0.550)$ & $(0.000)$ & $(126,103,93,65,11)$ \\
6 & -1444.759 & 0.68 & 3057.307 & 0.030 & 0.032 & 0.000 & $55,59,115,152,69,117$ \\
& $(-837.009)$ & $(0.79)$ & $(1823.129)$ & $(0.185)$ & $(0.189)$ & $(0.022)$ & $(121,106,95,61,11,4)$ \\
7 & -1432.413 & 0.73 & 3061.108 & - & - & - & $178,149,101,68,40,27,4$ \\
& $(-825.396)$ & $(0.74)$ & $(1825.224)$ & - & - & - & $(108,98,66,65,31,19,11)$ \\
\hline
\end{tabular}

Numbers in brackets represent the subsample of leaders who had not changed their organization during the data collection $(n=398)$

aBIC sample-size adjusted Bayesian Information Criterion, VLMR Vuong-Lo-Mendell-Rubin test, LMR Lo-Mendell-Rubin test, BLRT Bootstrap Likelihood Ratio Test 
after the seven-group solution, because the best Log Likelihood value was not replicated. This indicates that the model was no longer identifiable, which can result from using too many parameters (too many groups, in this case) in relation to the sample size. In both samples, the Log likelihood and aBIC values continued to decrease up to the seven groups. In the whole sample, BLRT remained significant for all the estimated models, which indicated that adding one more group $(k+1)$ provided a better fit to the data than the previous number of groups $(k)$. Among the leaders who had remained in the same organisation, BLRT increased for the six-group solution. The VLMR and LMR provided insignificant values for the three- and four-group solutions in the whole sample, and insignificant values after the three-group solution in the smaller sample, disagreeing with the other indices. However, in the whole sample, the five-group solution showed again a significant improvement in fit compared to the four-group solution (BLRT <0.05).

Because the fit indices provided mixed results, we used continued to inspect the different group solutions based on their content, clarity, and usefulness (see, e.g., Spurk et al. 2020). We found that the two-group solution was not able to capture the more detailed differences in ethical culture evaluations between leaders (mean scores were close to 4 in the first group for each time point, and close to 5 in the second group). The three-, and four-group solutions identified a distinctive, positive ethical culture pattern compared to the average patterns (with mean scores between 3 and $4)$. The five-group solution was able to identify a minority group of leaders with a low (mean scores below 3 ) and descending ethical culture pattern in addition to the high and average patterns. In the six-group solution (which was the last identifiable model in our data) no other subgroups emerged that would have brought any new, theoretically meaningful clarification to the five-group solution. Instead, the additional profile was relatively close to the "average" pattern in the prior solutions, splitting into minor differences in ethical culture score levels.

To summarise, based on both statistical indices and careful, content-related inspections, we decided on the five-group solution based on its superior ability to detect relevant and distinctive ethical culture patterns. Both samples equally supported this solution. Thus, we decided to use the full sample $(n=567)$ in our further analyses. This methodological choice was based on maintaining sufficient group sizes that would enable statistical testing of the outcome variables between them. Within this sample, the five-group solution had the highest entropy value $(0.75)$ and good posterior probabilities $(0.90,0.86,0.79,0.70$, and 0.91 ), indicating a sufficient probability of correctly belonging to one's designated group. The ethical culture patterns of these groups are shown in Fig. 2.

Twelve percent of the leaders were in the strong pattern, with the highest and increasing evaluations of ethical culture over time. The next three patterns differed from each other mainly in the absolute difference between the mean values in consecutive groups. The above average pattern included 27 percent of the leaders, with a somewhat high (close to a mean score of 5) and stable evaluations of ethical culture. Leaders in the average pattern (19\%; mean score close to 4.5$)$, followed by the below average $(39 \%$; mean score close to 4 ) pattern had still quite positive views of ethical culture with a small increase in their evaluations from T3 to T4. Three percent of the leaders belonged to the weak pattern, characterised by the lowest levels of perceived ethical culture (EC), which clearly decreased

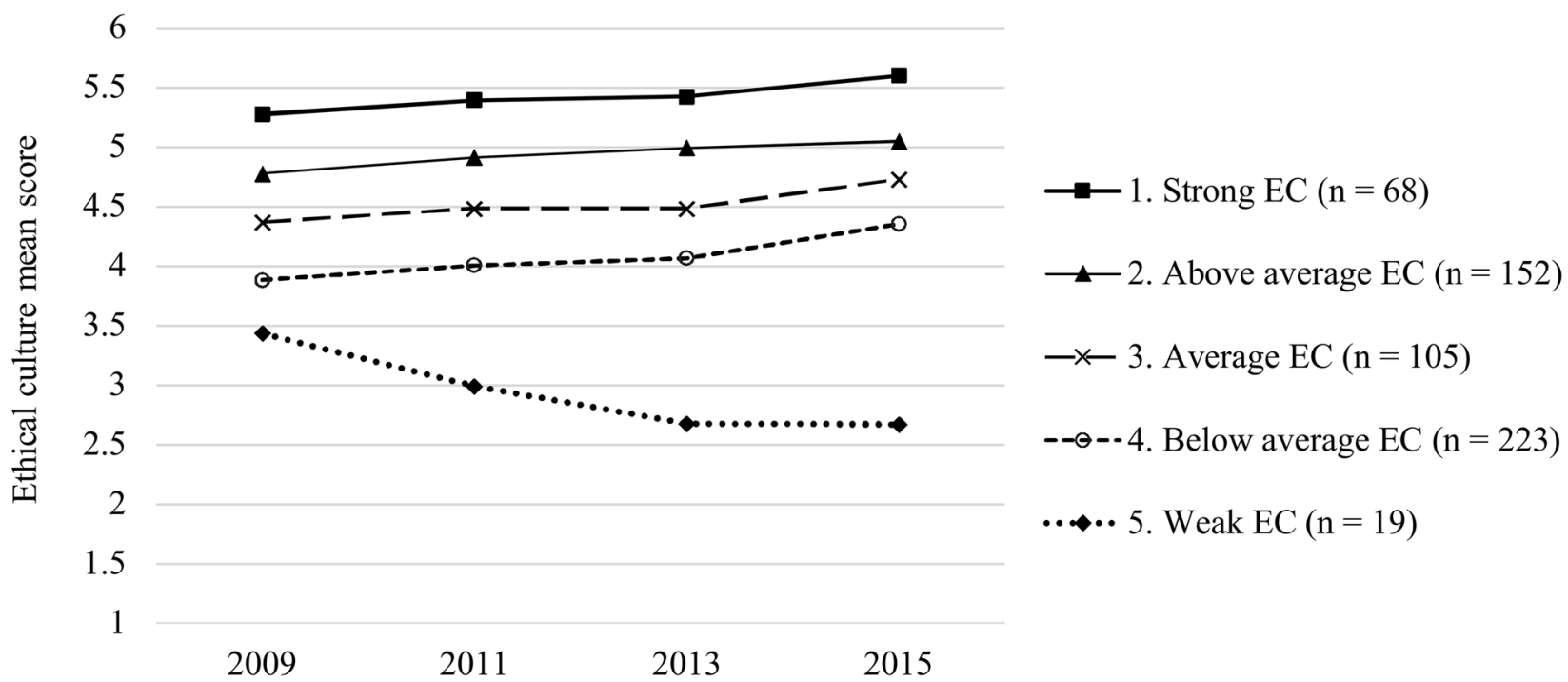

Fig. 2 Ethical culture (EC) patterns over time 
over time. Henceforth, these groups will be referred to as EC patterns.

The more detailed characteristics of the EC patterns are described in Table 5. The patterns had two significant differences in demographic properties. First, upper level (e.g., executive) leaders were overrepresented in the strong EC pattern and underrepresented in the below average pattern. Leaders from lower middle management were underrepresented in the above average EC pattern and overrepresented in the average pattern. Second, the leaders in the strong EC pattern were typically male; female leaders were underrepresented in this pattern. The opposite was true for the weak and below average EC patterns: leaders in these groups were typically female, and male leaders were underrepresented in them.

Finally, we investigated whether there were any differences in the ethical culture ratings between the leaders who had changed their organisation compared to those who had stayed in the same organisation during their study participation. This was done to ensure that using the full sample (including both "stayers" and "leavers") would not produce biased results when we proceeded to compare

Table 5 Characteristics of leaders in different corporate ethical virtue patterns

\begin{tabular}{|c|c|c|c|c|c|c|c|c|}
\hline & 1. Strong CEV & $\begin{array}{l}\text { 2. Above } \\
\text { average } \\
\text { CEV }\end{array}$ & 3. Average CEV & $\begin{array}{l}\text { 4. Below } \\
\text { average } \\
\mathrm{CEV}\end{array}$ & 5. Weak CEV & Estimate & $\mathrm{df}$ & $p$ \\
\hline$N$ & & & & & & $\chi^{2}$ & & \\
\hline \multicolumn{9}{|l|}{ Labour union } \\
\hline The finnish business school graduates & 39 & 68 & 45 & 100 & 10 & 4.49 & 4 & 0.344 \\
\hline Academic engineers and architects & 29 & 84 & 60 & 123 & 9 & & & \\
\hline \multicolumn{9}{|l|}{ Employer sector } \\
\hline Private & 58 & 129 & 80 & 170 & 14 & 19.65 & 16 & 0.237 \\
\hline Government & 3 & 5 & 9 & 22 & 1 & & & \\
\hline Municipality & 3 & 9 & 9 & 22 & 2 & & & \\
\hline Own company & 3 & 8 & 4 & 3 & 0 & & & \\
\hline Association & 1 & 1 & 3 & 5 & 1 & & & \\
\hline Employment field & & & & & & 29.85 & 28 & 0.371 \\
\hline Industry & 19 & 65 & 38 & 94 & 8 & & & \\
\hline $\begin{array}{l}\text { Telecommunications or data process- } \\
\text { ing }\end{array}$ & 10 & 19 & 14 & 35 & 3 & & & \\
\hline Business services or renting & 13 & 16 & 11 & 24 & 2 & & & \\
\hline Public administration & 2 & 9 & 14 & 23 & 2 & & & \\
\hline Finance and insurance & 11 & 13 & 8 & 12 & 0 & & & \\
\hline Commerce and trade & 6 & 13 & 9 & 10 & 1 & & & \\
\hline Education & 3 & 4 & 2 & 6 & 1 & & & \\
\hline Other & 4 & 13 & 9 & 19 & 2 & & & \\
\hline Leadership level & & & & & & 31.20 & 23 & 0.002 \\
\hline Upper management & $18_{\mathrm{T}}$ & 22 & 14 & $18_{\mathrm{AT}}$ & 0 & & & \\
\hline Management & 22 & 58 & 30 & 72 & 7 & & & \\
\hline Upper middle management & 21 & 55 & 36 & 92 & 6 & & & \\
\hline Lower middle management & 7 & $17_{\mathrm{AT}}$ & $25_{\mathrm{T}}$ & 41 & 6 & & & \\
\hline Direct subordinates & & & & & & 6.35 & 4 & 0.175 \\
\hline Yes & 61 & 125 & 84 & 172 & 13 & & & \\
\hline No & 7 & 27 & 21 & 51 & 5 & & & \\
\hline Gender & & & & & & 15.03 & 4 & 0.005 \\
\hline Male & $55_{\mathrm{T}}$ & 112 & 72 & $138_{\mathrm{AT}}$ & $9_{\mathrm{AT}}$ & & & \\
\hline Female & $13_{\mathrm{AT}}$ & 40 & 33 & $85_{\mathrm{T}}$ & $10_{\mathrm{T}}$ & & & \\
\hline$M$ & & & & & & $F$ & & \\
\hline Age & 46.03 & 45.65 & 45.36 & 46.01 & 46.68 & 0.16 & 4,562 & 0.959 \\
\hline Organisational tenure & 9.88 & 11.33 & 11.60 & 9.86 & 7.47 & 1.72 & 4,562 & 0.143 \\
\hline Work experience in current task & 4.54 & 4.01 & 5.31 & 4.00 & 4.04 & 1.80 & 4,560 & 0.128 \\
\hline
\end{tabular}

$C E V$ corporate ethical virtues, $T$ typical, $A T$ atypical, adjusted residual $>|2|$ 
the leaders' in the different EC patterns. The results from analysis of variance showed that there were no significant differences between the ethical culture ratings at $\mathrm{T} 2$ $[F(1,461)=2.44, p=0.119]$, at T3 $[F(1,401)=0.85$, $p=0.770]$, or at $\mathrm{T} 4[F(1,235)=0.57, p=0.451]$. Even so, we controlled for the potential effect of job change in our subsequent analyses to ensure that any changes in wellbeing would not be a result of the potential job change. That is, we used a dummy variable of whether or not the leader had changed his or her job (yes/no) at some point during the data collection period (between T1-T2, T2-T3, and T3-T4) as a covariate in the HLM analyses.

\section{Differences Between Well-Being in the Ethical Culture Patterns}

\section{Group Effects}

We found that there were a high number of statistically significant pairwise differences in well-being outcomes between the EC patterns at each time point (see Table 6). The main group effects that were repeated across different outcome variables and across time (all the detailed results are available from the authors on request). Firstly, as seen in Figs. 3, $4,5,6$, leaders in the strong and above average EC patterns tended to evaluate their experiences of ethical dilemmas,

Table 6 Well-being outcomes in the five corporate ethical virtue patterns at 2009 (T1), 2011 (T2), 2013 (T3), and 2015 (T4)

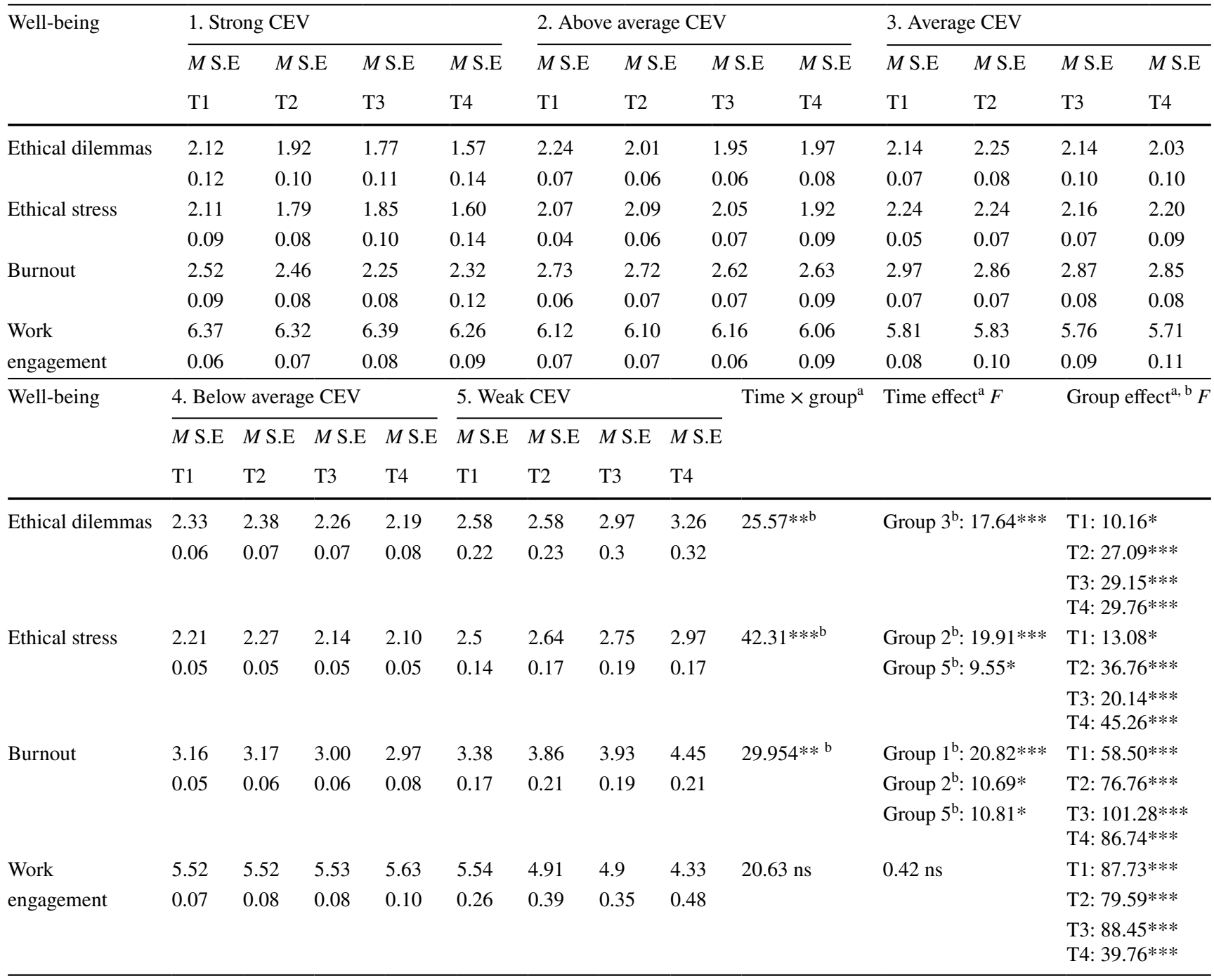

Results from Hierarchical Linear Modelling

CEV corporate ethical virtues

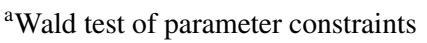

${ }^{\mathrm{b}}$ Pairwise differences are specified in Figs. 2, 3, 4, 5

$* p<0.05, * * p<0.01, * * * p<0.001$ 


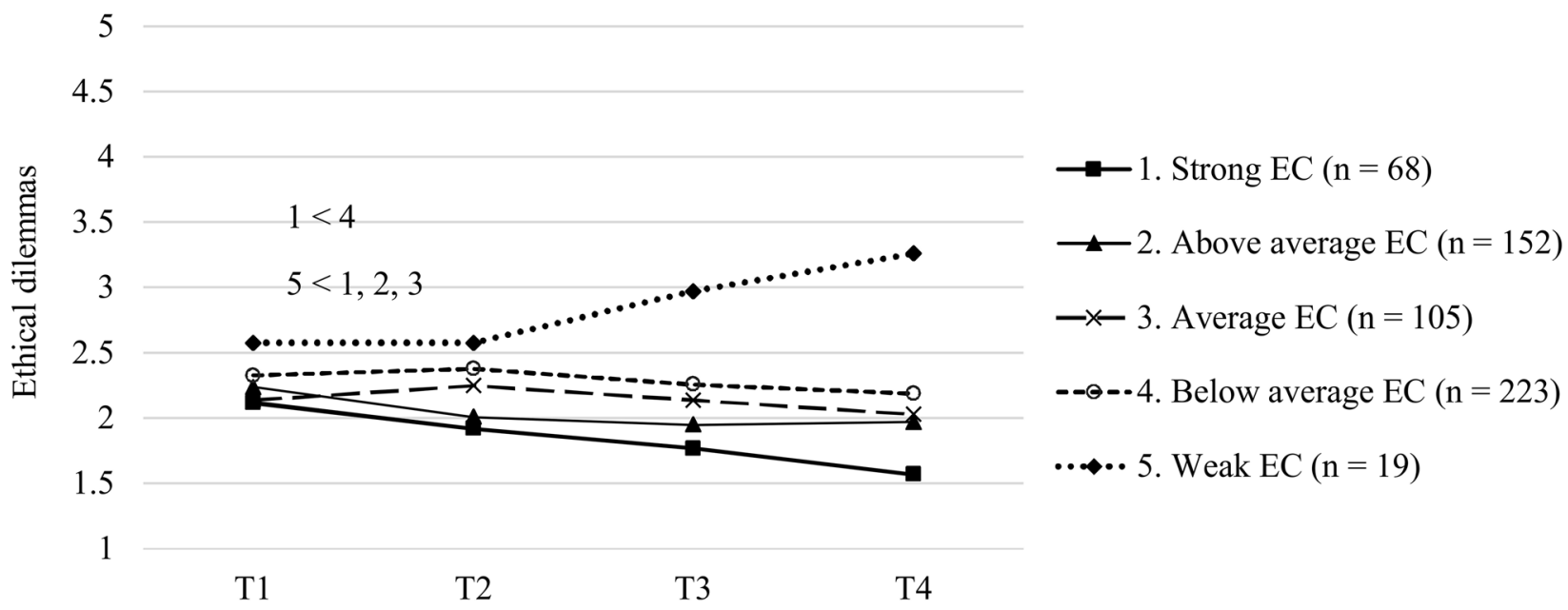

Fig. 3 Changes in ethical dilemma frequency within five patterns of ethical culture (EC). Pairwise differences refer to significant differences in slopes between patterns (between two time points)

4

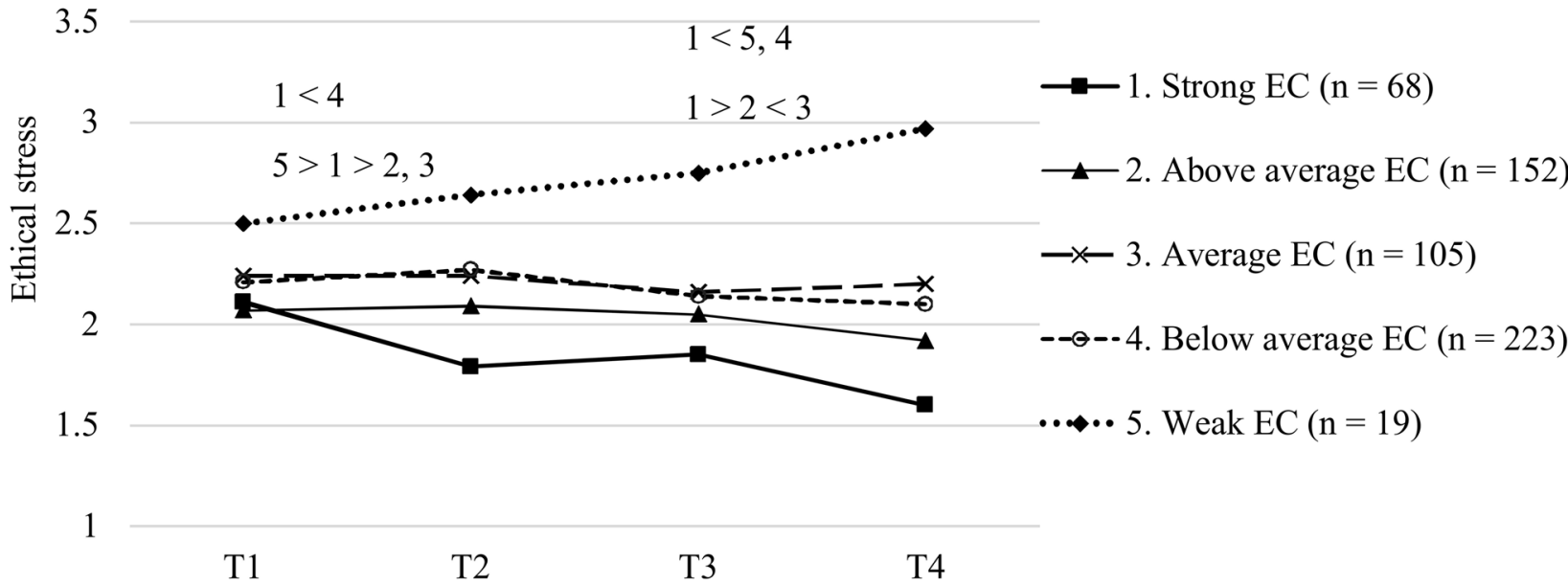

Fig. 4 Changes in ethical stress within the five patterns of ethical culture (EC). Pairwise differences refer to significant differences in slopes between patterns (between two time points)

stress, and burnout as lower than did leaders in the other three patterns, and their work engagement as higher than the others. This supported Hypothesis 1 . Secondly, leaders in the weak EC pattern had higher evaluations of ethical dilemmas, stress, and burnout and lower evaluations of work engagement than leaders in the other patterns, supporting Hypothesis 2 . These group differences were significant within most of the separate four time points.

\section{Time Effects}

Next, we investigated time effects, i.e., changes in well-being over time within each EC pattern. In the above average EC pattern, leaders experienced fewer ethical dilemmas at $\mathrm{T} 2$ and T4 than at T1. Similarly, in the strong EC pattern, leaders experienced less ethical stress at $\mathrm{T} 2$ and $\mathrm{T} 4$ than at $\mathrm{T} 1$. Also in the below average pattern leaders reported less ethical stress at $\mathrm{T} 3$ than at $\mathrm{T} 2$ and less at $\mathrm{T} 4$ than at $\mathrm{T} 1$. Burnout increased in the weak EC pattern: these leaders experienced more burnout at $\mathrm{T} 2$ than at $\mathrm{T} 1$, and more at $\mathrm{T} 4$ than at $\mathrm{T} 1$ or T3. The opposite was observed for the high and below average patterns: they experienced less burnout at $\mathrm{T} 3$ than at $\mathrm{T} 2$. There was small decrease in work engagement from $\mathrm{T} 1$ to T2 $(-0.63)$ and from T3 to T4 $(-0.57)$ within the weak EC pattern (see Fig. 6), but it did not reach statistical significance, probably due to the small group size $(n=19)$. 


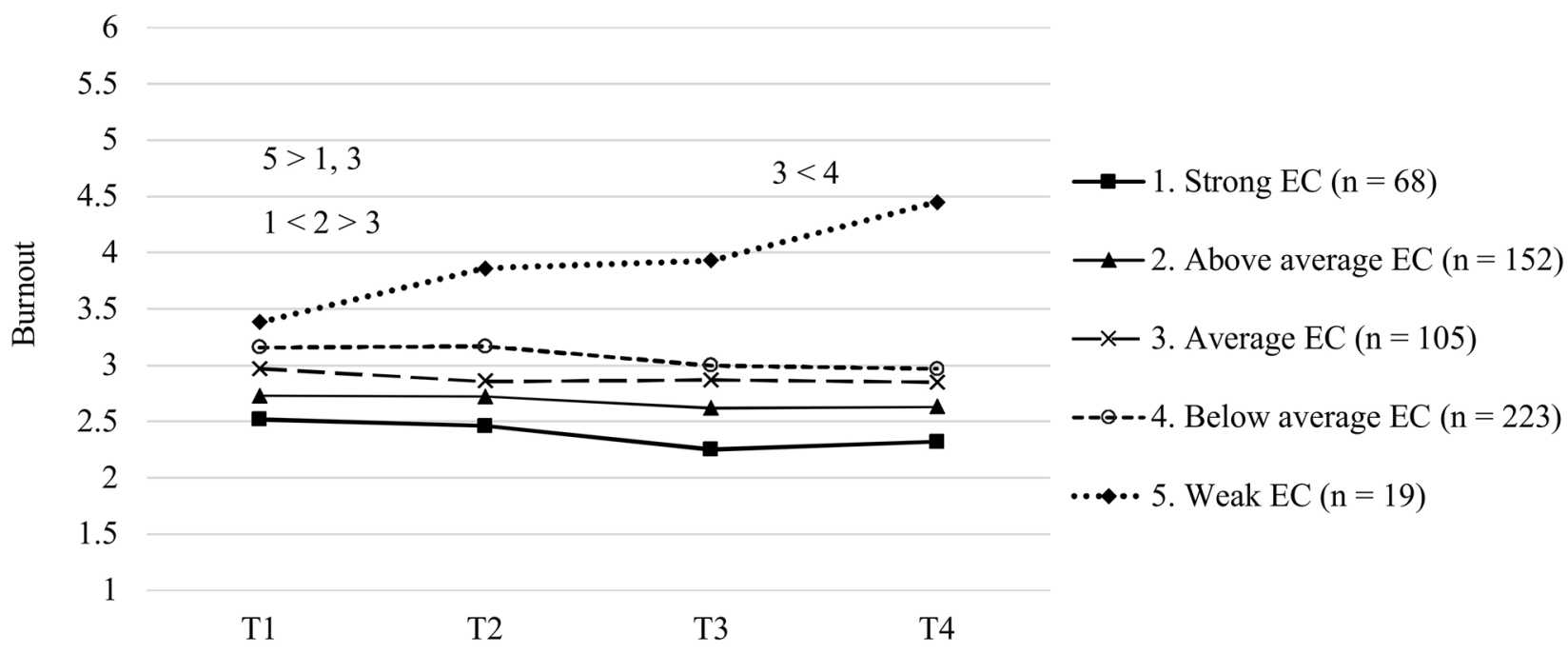

Fig. 5 Changes in burnout within five patterns of ethical culture (EC). Pairwise differences refer to significant differences in slopes between patterns (between two time points)

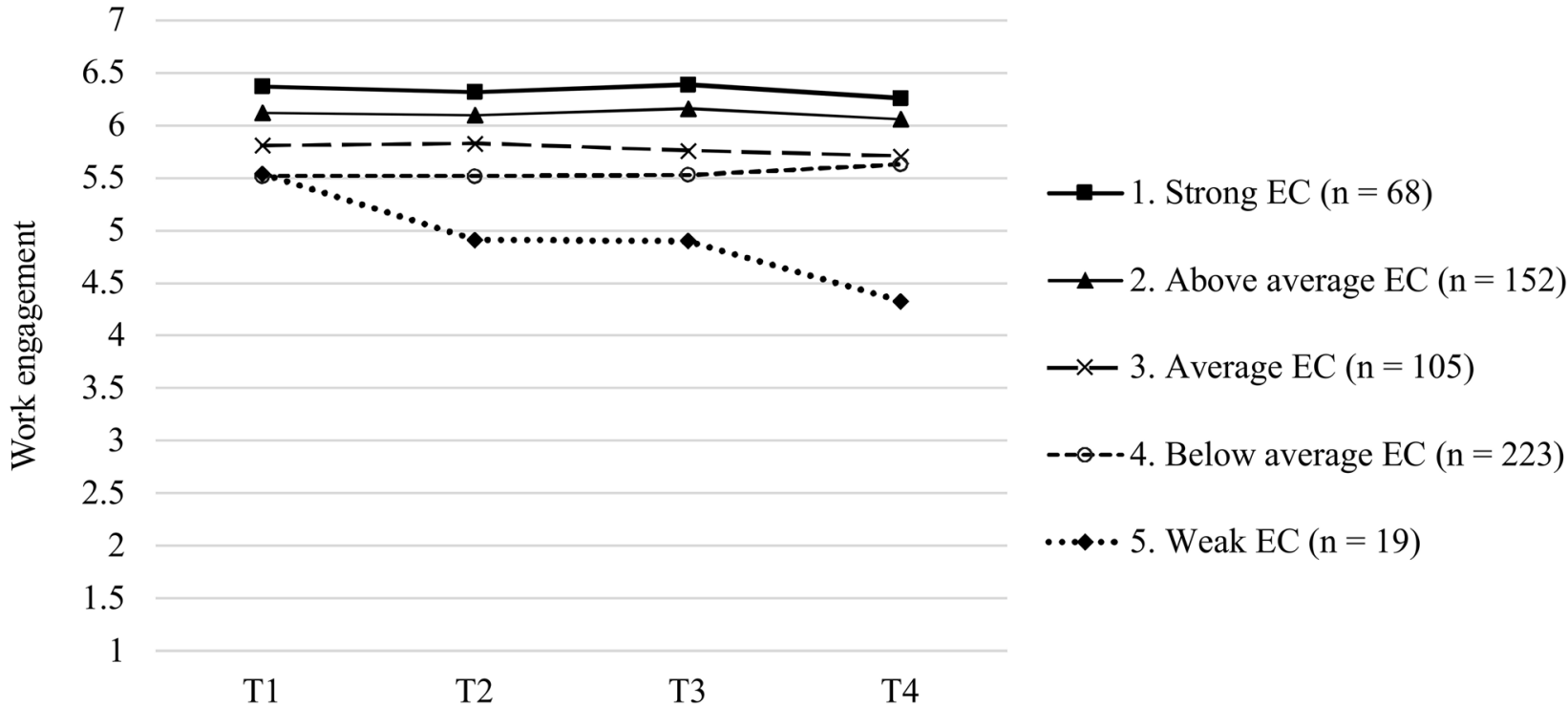

Fig. 6 Changes in work engagement within five patterns of ethical culture (EC). No significant differences in slopes between patterns were found

\section{Interaction Effects}

Finally, we found significant interactions which showed that the change over time in ethical dilemmas, stress, and burnout was different between EC patterns. Based on post hoc Monte Carlo simulations (with 10,000 replications), we calculated the statistical power for these analyses: all ethical culture patterns were compared with each other concerning the change in the outcome variables over time between them. The power of these parameters were between 0.07 and 0.57 for ethical dilemmas, $0.06-0.95$ for ethical stress, $0.06-0.76$ for burnout, and $0.07-0.82$ for work engagement.
The Wald test estimates are presented in Table 6. We found several significant pairwise differences regarding the amount of change (different slopes) between the patterns, which are included in Figs. 3, 4, 5, 6. Within the pattern of weak ethical culture, the experienced level of ethical dilemmas, stress, and burnout increased over time, even when the negative slope, i.e., decline in ethical culture strength ceased between $\mathrm{T} 3$ and T4. Vice versa, there was a continuous decline in ethical dilemmas and ethical stress in the strong EC pattern, although the positive slope in ethical culture strength was less steep between T3 to T4. The mean change in ethical culture strength within the strong pattern was only +0.18 , 
whereas it was +0.29 in the below average EC and +0.25 in the average EC patterns during that same time phase. Thus, these differences can be summarised as a cumulative effect of ethical culture strength for well-being both negatively and positively over time, partly supporting Hypotheses 3 and 4 .

\section{Discussion}

We investigated the temporal dynamics in ethical culture evaluations and experienced well-being at work by following the self-evaluations of a sample of leaders across a period of 6 years. We found that there were longitudinal, concurrent relations between ethical culture patterns and well-being. Those leaders who experienced ethical culture as being on the weakest level also reported less favourable well-being over time, whereas leaders in the strongest ethical culture pattern experienced the highest level of work engagement and a decreasing level of ethical strain. We will next discuss our findings in more detail.

\section{Ethical Culture Can Lead to Gain and Loss Cycles in Well-Being}

Our findings were mostly consistent with the main processes of resource loss and gain in the COR theory (Hobfoll et al. 2018). First, we found that a minority of leaders experienced their organisational environment as being characterised by a weak ethical culture which also decreased over time. These leaders reported the highest level of ethical dilemmas, stress, and burnout. In addition, they experienced a continuous increase in these negative outcomes, even though the level of ethical culture ceased to fall, and stabilised during the last phase of the study. This agrees with the COR theory's corollary about the resource loss cycle, where resource depletion leads to a negative spiral (Hobfoll et al. 2018), and supports the meta-analytic evidence of synchronous stressor-strain effects that tend to strengthen over time (Ford et al. 2014). Thus, there seems to be a cumulative effect of experiencing a continuous low level of ethical culture in one's work place, where even a positive turn does not translate directly into concurrent positive changes in well-being. Rather, there continued to be negative effects on well-being, despite the positive change in ethical culture evaluations.

On the positive side, ethical culture consistently cooccurred with positive well-being outcomes. Leaders in the strong ethical culture pattern reported the lowest levels of ethical dilemmas, stress, and burnout, and the highest level of engagement at work across the study intervals. There was also a slight decrease regarding the reported ethical dilemma frequency and ethical stress magnitude among these leaders, although these changes over time were smaller than the negative outcomes. This is in line with the COR theory, which states that positive resource gain spirals tend to be weaker than loss cycles (Hobfoll 2001).

\section{Contributions}

Our findings contribute to the neglected issue of time in ethical culture studies within organisations. When we compare our findings with the only existing longitudinal investigation of ethical culture stability and change in organisations (Huhtala et al. 2016), we conclude that different results can be obtained depending on the length of the time intervals used. Huhtala et al. (2016) followed a sample of leaders for 2 years and found that although less typical than stable patterns, there were two patterns where leaders reported either a clear reduction or a clear increase in ethical culture evaluations over time. In their study, an increase in the level of ethical culture associated with a buffering effect against more negative well-being outcomes, whereas experiences of decreasing ethical culture were associated with an increase in cynical attitudes towards work over the 2-year follow-up period (Huhtala et al. 2016). Unlike Huhtala et al. (2016), we did not find any change patterns that presented ethical culture as being clearly dynamic by nature. Our 6-year time lag showed that all patterns included a slight increase in the overall level of ethical culture during the last time interval, but no patterns with distinctive patterns of change across the whole follow-up period were identified (for example, a continuous increase in the level of ethical culture during each interval, or a combination of increase and decrease in ethical culture over time within one pattern). Taken together, these results highlight the importance of planning appropriate research designs to capture longitudinal changes, as using different time frames may produce different results.

Compared with Huhtala et al. (2016), we included wellbeing outcomes that are more closely linked to ethical culture, that is, ethical dilemmas and ethical stress, and found that these outcomes showed more temporal changes than was evident for burnout and work engagement. This may indicate that ethical dilemmas and stress are more responsive to the ethical environment, as the ethical culture can have direct effects on how often one faces ethical dilemmas at work, and closely affect how much stress these dilemmas cause (e.g., through the levels of discussability and shared support for ethical decisions). In contrast, the levels of burnout and engagement can be affected by a variety of complementary or alternative factors (such as work overload, role conflict, or autonomy), and they are more likely to show within-individual stability over time (Schaufeli et al. 2011; Seppälä et al. 2015). This should be taken into account when planning practical applications based on our findings: it is likely that when efforts are taken to strengthen the ethical culture within organisations, leaders (or employees) might first experience a decrease in ethical strain, which could 
later contribute to fewer feelings of burnout or exhaustion at work. This kind of mediated association has been found in previous research (Huhtala et al. 2011).

An important contribution of using the person-oriented approach was that we found a minority group of leaders who experienced ethical culture to be on a weak level and decrease over time. These low level evaluations of ethical culture were, however, associated with increased experiences of ethical dilemmas, ethical stress, and burnout, and with decreased engagement at work. This atypical finding could have been overlooked if we had not used the profile analysis, which is able to detect also minority patterns among study participants. Using only a variable-centred design, which predicts well-being with the mean levels of ethical culture across the whole sample, could have left this association between the atypical ethical culture pattern and poor well-being undetected.

\section{Limitations and Future Studies}

There are some limitations that need to be considered when interpreting and applying our study results. First, our interest (and contribution) was to use the person-centred design in order to investigate more detailed, various patterns of change in ethical culture evaluations over time and to detect associations related to minority groups. Using variablecentred analyses could be used to test the causal relationships between ethical culture and different outcomes over time. However, it might be difficult to collect samples that provide enough variance that allows to detect predictive relationships across whole study populations, if only a minority of participants experience major changes in ethical culture evaluations over time. Relatedly, one limitation of our study was the small statistical power that resulted from comparing small subgroups with each other. Nevertheless, future studies could apply both variable and person oriented approaches to gain more empirical evidence on the longitudinal outcomes of ethical culture.
Second, our data was based on self-reports, which raises the risk for common method variance or consistent answers to the questionnaires, which could have affected the magnitude of our estimates. The associations we found may also be partly caused by environmental or personal effects that were not included in our model. We acknowledge these endogeneity issues (Ketokivi and McIntosh 2017), and do not claim that our findings are free from potential bias. However, as the longitudinal research on ethical organisational culture is still only emerging, we argue that our findings make an important contribution to the field because they provide novel evidence of the concurrent relations between ethical culture strength and well-being over a period of 6 years, including atypical minority patterns.

Finally, this study focused on ethical culture as an organisational resource that was found to have associations with individual well-being over time. There might also be other personal or job-related resources that could buffer or boost these effects. For example, if an employee experiences a decrease in the level of ethical culture in their organisation, personal resources such as strong moral identity or moral agency (Huhtala et al. 2019; Weaver 2006) might reduce the negative effect that this environmental change has on their well-being. Alternatively, if the organisation has a strong ethical culture, its positive effects on personal wellbeing could be increased when a person experiences a good person-environment fit or commitment to their job. There are, then, numerous possibilities for moderated associations that remain to be tested in future studies, especially with longitudinal designs.

\section{Appendix}

See Table 7. 


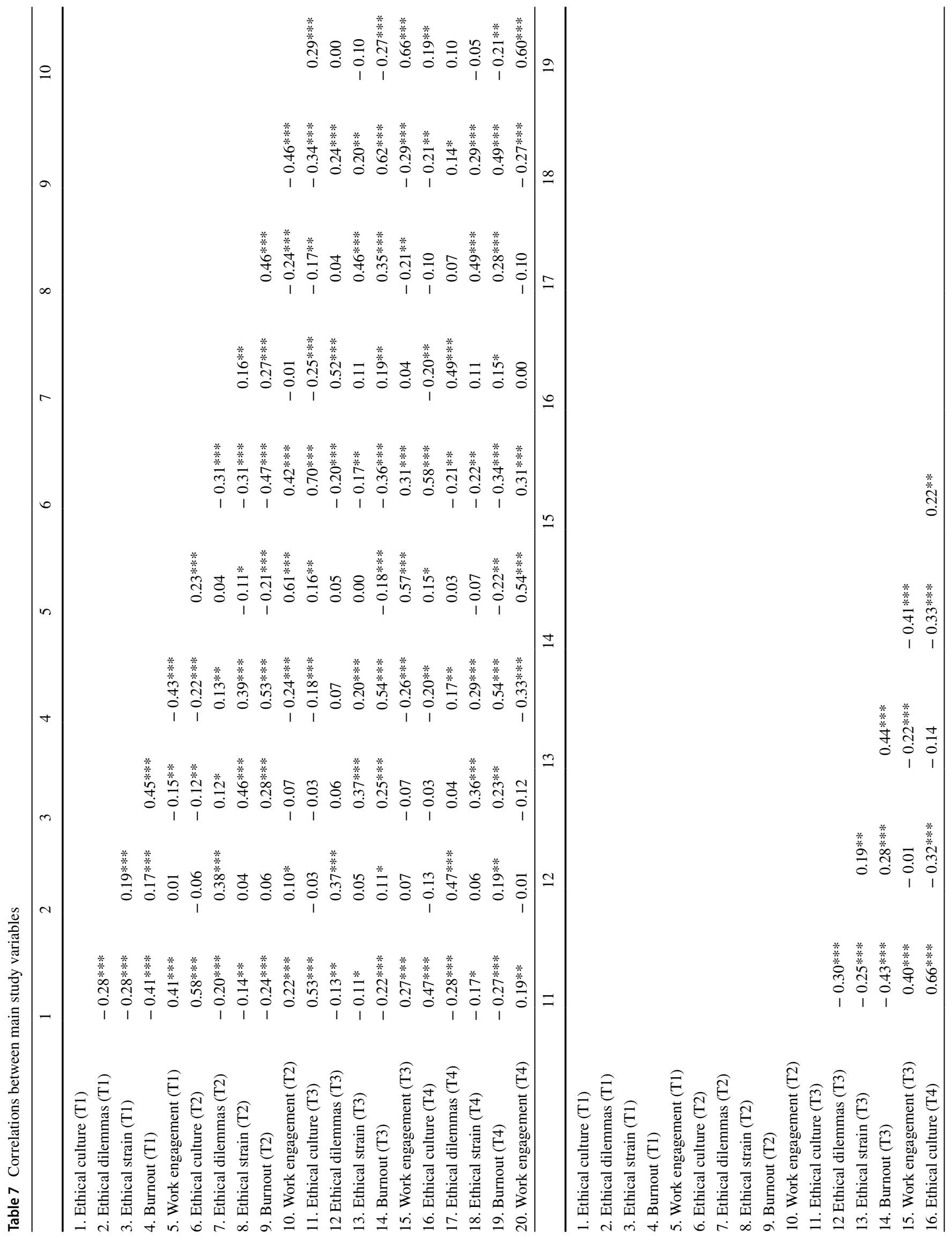


Funding Open Access funding provided by University of Jyväskylä (JYU). This work was supported by the Academy of Finland under Grant Nos. 294428 and 308336; and by the Finnish Work Environment Fund under Grant Nos. 108124 and 110104.

\section{Compliance with Ethical Standards}

Conflict of interest The authors declare that they have no conflict of interest.

Ethical Approval All procedures performed in studies involving human participants were in accordance with the ethical standards of the institutional and/or national research committee and with the 1964 Helsinki declaration and its later amendments or comparable ethical standards.

Informed Consent Informed consent was obtained from all individual participants included in the study.

Open Access This article is licensed under a Creative Commons Attribution 4.0 International License, which permits use, sharing, adaptation, distribution and reproduction in any medium or format, as long as you give appropriate credit to the original author(s) and the source, provide a link to the Creative Commons licence, and indicate if changes were made. The images or other third party material in this article are included in the article's Creative Commons licence, unless indicated otherwise in a credit line to the material. If material is not included in the article's Creative Commons licence and your intended use is not permitted by statutory regulation or exceeds the permitted use, you will need to obtain permission directly from the copyright holder. To view a copy of this licence, visit http://creativecommons.org/licenses/by/4.0/.

\section{References}

Baker, T. L., Hunt, T. G., \& Andrews, M. C. (2006). Promoting ethical behavior and organizational citizenship behaviors: The influence of corporate ethical values. Journal of Business Research, 59, 849-857.

Bakker, A. B., Demerouti, E., \& Sanz-Vergel, A. I. (2014). Burnout and work engagement: The JD-R approach. Annual Review of Organisational Psychology and Organisational Behaviour, 1, 389-411.

Bird, F., \& Waters, J. A. (1987). The nature of managerial moral standards. Journal of Business Ethics, 6, 1-13.

Bliese, P. D., Edwards, J. R., \& Sonnentag, S. (2017). Stress and wellbeing at work: A century of empirical trends reflecting theoretical and societal influences. Journal of Applied Psychology, 102, 389-402.

Celeux, G., \& Soromenho, G. (1996). An entropy criterion for assessing the number of clusters in a mixture model. Journal of Classification, 13, 195-212.

Crilly, D. (2013). Corporate social responsibility: a multilevel explanation of why managers do good. In P. C. Fiss, B. Cambré, \& A. Marx (Eds.), Configural theory and methods in organizational research (pp. 181-205). London: Emerald.

DeBode, J. D., Armenakis, A. A., Feild, H. S., \& Walker, A. G. (2013). Assessing ethical organizational culture: Refinement of a scale. The Journal of Applied Behavioral Science, 49, 460-484.

DeTienne, K., Agle, B., Phillips, J., \& Ingerson, M. (2012). The impact of moral stress compared to other stressors on employee fatigue, job satisfaction, and turnover: An empirical investigation. Journal of Business Ethics, 110, 377-391. 
Elo, A.-L., Leppänen, A., \& Jahkola, A. (2003). Validity of a singleitem measure of stress symptoms. Scandinavian Journal of Work, Environment and Health, 29, 444-451.

Ford, M. T., Matthews, R. A., Wooldridge, J. D., Mishra, V., Kakar, U. M., \& Strahan, S. R. (2014). How do occupational stressorstrain effects vary with time? A review and meta-analysis of the relevance of time lags in longitudinal studies. Work \& Stress, 28 , 9-30.

Halbesleben, J. R., Neveu, J. P., Paustian-Underdahl, S. C., \& Westman, M. (2014). Getting to the "COR" understanding the role of resources in conservation of resources theory. Journal of Management, 40, 1334-1364.

Hobfoll, S. E. (1989). Conservation of resources: A new attempt at conceptualizing stress. American Psychologist, 44, 513-524.

Hobfoll, S. E. (2001). The influence of culture, community, and the nested-self in the stress process: Advancing conservation of resources theory. Applied Psychology, 50, 337-421.

Hobfoll, S. E., Halbesleben, J., Neveu, J. P., \& Westman, M. (2018). Conservation of resources in the organisational context: The reality of resources and their consequences. Annual Review of Organisational Psychology and Organisational Behaviour, 5, 103-128.

Howard, M. C., \& Hoffman, M. E. (2018). Variable-centered, personcentered, and person-specific approaches: Where theory meets the method. Organizational Research Methods, 21, 846-876.

Huhtala, M., Feldt, T., Lämsä, A.-M., Mauno, S., \& Kinnunen, U. (2011). Does the ethical culture of organisations promote managers' occupational well-being? Investigating indirect links via ethical strain. Journal of Business Ethics, 101, 231-247.

Huhtala, M., Kangas, M., Kaptein, M., \& Feldt, T. (2018). The shortened Corporate Ethical Virtues scale: Measurement invariance and mean differences across two occupational groups. Business Ethics: A European Review, 27, 238-247.

Huhtala, M., Kaptein, M., \& Feldt, T. (2016). How perceived changes in the ethical culture of organisations influence the well-being of managers: A two-year longitudinal study. European Journal of Work and Organisational Psychology, 25, 335-352.

Huhtala, M., Lämsä, A.-M., \& Feldt, T. (2019). Applying the identity status paradigm to managers' moral identity. Scandinavian Journal of Work and Organizational Psychology, 4, 1-14.

Huhtala, M., Tolvanen, A., Mauno, S., \& Feldt, T. (2014). The associations between ethical organizational culture, burnout and engagement: A multilevel study. Journal of Business and Psychology, 30, 399-414.

Jameton, A. (1984). Nursing practice: The ethical issues. Englewood Cliffs, NJ: Prentice Hall.

Jaramillo, F., Mulki, J. P., \& Boles, J. S. (2013). Bringing meaning to the sales job: The effect of ethical climate and customer demandingness. Journal of Business Research, 66, 2301-2307.

Kangas, M., Feldt, T., Huhtala, M., \& Rantanen, J. (2014). The Corporate Ethical Virtues scale: Factorial invariance across organizational samples. Journal of Business Ethics, 124, 161-171.

Kangas, M., Kaptein, M., Huhtala, M., Lämsä, A. M., Pihlajasaari, P., \& Feldt, T. (2018). Why do managers leave their organisation? Investigating the role of ethical organisational culture in managerial turnover. Journal of Business Ethics, 153, 707-723.

Kaptein, M. (1998). Ethics management: Auditing and developing the ethical context of organisations. Dordrecht: Springer.

Kaptein, M. (2008). Developing and testing a measure for the ethical culture of organisations: The corporate ethical virtues model. Journal of Organisational Behaviour, 29, 923-947.

Kaptein, M. (2011). Understanding unethical behaviour by unraveling ethical culture. Human Relations, 64, 843-869.

Kaptein, M. (2017). When organizations are too good: Applying Aristotle's doctrine of the mean to the corporate ethical virtues model. Business Ethics: A European Review, 26, 300-311.
Ketokivi, M., \& McIntosh, C. N. (2017). Addressing the endogeneity dilemma in operations management research: Theoretical, empirical, and pragmatic considerations. Journal of Operations Management, 52, 1-14.

Maas, C. J. M., \& Snijders, T. A. B. (2003). The multilevel approach to repeated measures for complete and incomplete data. Quality \& Quantity, 37, 71-89.

Mäkikangas, A., Kinnunen, U., Feldt, T., \& Schaufeli, W. (2016). The longitudinal development of employee well-being: A systematic review. Work \& Stress, 30, 46-70.

Marsh, H. W., Hau, K. T., Balla, J. R., \& Grayson, D. (1998). Is more ever too much? The number of indicators per factor in confirmatory factor analysis. Multivariate Behavioral Research, 33(2), 181-220. https://doi.org/10.1207/s15327906mbr3302_1.

Mayer, D. M. (2014). A review of the literature on ethical climate and culture. In B. Schneider \& K. M. Barbera (Eds.), The Oxford handbook of organizational climate and culture (pp. 415-442). Oxford: Oxford University Press.

McLeod, M. S., Payne, G. T., \& Evert, R. E. (2016). Organisational ethics research: A systematic review of methods and analytical techniques. Journal of Business Ethics, 134, 429-443.

Mulki, J., \& Lassk, F. G. (2019). Joint impact of ethical climate and external work locus of control on job meaningfulness. Journal of Business Research, 99, 46-56.

Muthén, L. K., \& Muthén, B. O. (1998-2017). Statistical analysis with latent variables. User's guide (8th ed.). Los Angeles, CA: Muthén \& Muthén.

Näätänen, P., Aro, A., Matthiesen, S., \& Salmela-Aro, K. (2003). Bergen Burnout Indicator 15. Helsinki: Edita.

Nash, L. L. (1993). Good intentions aside. A manager's guide to resolving ethical problems. Boston: Harvard Business School Press.

Nylund, K. L., Asparouhov, T., \& Muthén, B. O. (2007). Deciding on the number of classes in latent class analysis and growth mixture modeling: A Monte Carlo simulation study. Structural Equation Modeling: A Multidisciplinary Journal, 14, 535-569.

Salmela-Aro, K., Näätänen, P., \& Nurmi, J. (2004). The role of work related personal projects during two burnout interventions: A longitudinal study. Work \& Stress, 18, 208-230.

Salmela-Aro, K., Rantanen, J., Hyvönen, K., Tilleman, K., \& Feldt, T. (2011). Bergen Burnout Inventory: Reliability and validity among Finnish and Estonian managers. International Archives of Occupational and Environmental Health, 84, 635-645.

Satorra, A., \& Bentler, P. M. (1999). A scaled difference chi-square test statistic for moment structure analysis. Retrieved from http:// www.econ.upf.edu/docs/papers/downloads/412.pdf.

Schaufeli, W. B., \& Bakker, A. B. (2004). Job demands, job resources, and their relationship with burnout and engagement: A multisample study. Journal of Organizational Behavior, 25, 293-315.

Schaufeli, W. B., Bakker, A. B., \& Salanova, M. (2006). The measurement of work engagement with a short questionnaire: A crossnational study. Educational and Psychological Measurement, 66, 701-716.

Schaufeli, W. B., Bakker, A. B., \& Van Rhenen, W. (2009). How changes in job demands and resources predict burnout, work engagement, and sickness absenteeism. Journal of Organisational Behaviour, 30, 893-917.

Schaufeli, W. B., Maassen, G. H., Bakker, A. B., \& Sixma, H. J. (2011). Stability and change in burnout: A 10-year follow-up study among primary care physicians. Journal of Occupational and Organisational Psychology, 84, 248-267.

Schwepker, C. H. (2001). Ethical climate's relationship to job satisfaction, organizational commitment, and turnover intention in the salesforce. Journal of Business Research, 54, 39-52.

Seppälä, P., Mauno, S., Feldt, T., Hakanen, J., Kinnunen, U., Tolvanen, A., et al. (2009). The construct validity of the Utrecht work 
engagement scale: Multisample and longitudinal evidence. Journal of Happiness Studies, 10(4), 459-481. https://doi.org/10.1007/ s10902-008-9100-y.

Seppälä, P., Hakanen, J., Mauno, S., Perhoniemi, R., Tolvanen, A., \& Schaufeli, W. (2015). Stability and change model of job resources and work engagement: A seven-year three-wave follow-up study. European Journal of Work and Organisational Psychology, 24, 360-375

Shipp, A. J., \& Cole, M. S. (2015). Time in individual-level organisational studies: What is it, how is it used, and why isn't it exploited more often? Annual Review of Organisational Psychology and Organisational Behaviour, 2, 237-260.

Snijders, T. A. B., \& Bosker, R. J. (1993). Standard errors and sample sizes for two-level research. Journal of Educational Statistics, $18,237-259$

Spurk, D., Hirschi, A., Wang, M., Valero, D., \& Kauffeld, S. (2020). Latent profile analysis: A review and "how to" guide of its application within vocational behavior research. Journal of Vocational Behavior. https://doi.org/10.1016/j.jvb.2020.103445.

Treviño, L. K. (1986). Ethical decision-making in organisations: A person-situation interactionist model. Academy of Management Review, 11, 601-617.

Treviño, L. K., \& Weaver, G. R. (2003). Managing ethics in business organizations: Social scientific perspective. Palo Alto: Stanford University Press.

Vandenberg, R. J., \& Lance, C. E. (2000). A review and synthesis of the measurement invariance literature: Suggestions, practices, and recommendations for organizational research. Organizational Research Methods, 3, 4-70.

Van der Wal, Z., De Graaf, G., \& Lasthuizen, K. (2008). What's valued most? Similarities and differences between the organisational values of the public and private sector. Public Administration, $86,465-482$.

Victor, B., \& Cullen, J. B. (1987). A theory and measure of ethical climate in organizations. In W. C. Frederick (Ed.), Research in corporate social performance and policy (pp. 51-71). Greenwich, CT: JAI Press.

Waters, J. A., \& Bird, F. (1987). The moral dimension of organisational culture. Journal of Business Ethics, 6, 15-22.

Weaver, G. R. (2006). Virtue in organizations: Moral identity as a foundation for moral agency. Organization Studies, 27(3), 341-368. https://doi.org/10.1177/0170840606062426.

Wilkinson, J. M. (1987). Moral distress in nursing practice: Experience and effect. Nursing Forum, 23, 16-29.

Woo, S. E., Jebb, A. T., Tay, L., \& Parrigon, S. (2018). Putting the "person" in the center: Review and synthesis of person-centered approaches and methods in organizational science. Organizational Research Methods, 21, 814-845.

Publisher's Note Springer Nature remains neutral with regard to jurisdictional claims in published maps and institutional affiliations. 